\title{
Article \\ Rootstocks Overexpressing StNPR1 and StDREB1 Improve Osmotic Stress Tolerance of Wild-Type Scion in Transgrafted Tobacco Plants
}

\author{
Yasmine S. Hezema ${ }^{1,2}{ }^{\mathbb{D}}$, Mukund R. Shukla ${ }^{1} \mathbb{D}$, Alok Goel ${ }^{1}$, Murali M. Ayyanath ${ }^{1} \mathbb{D}$, Sherif M. Sherif ${ }^{3, *(\mathbb{D})}$ \\ and Praveen K. Saxena $1, * \mathbb{D}$ \\ 1 Gosling Research Institute for Plant Preservation, Department of Plant Agriculture, University of Guelph, \\ Guelph, ON N1G 2W1, Canada; yhezema@uoguelph.ca (Y.S.H.); mshukla@uoguelph.ca (M.R.S.); \\ alok@uoguelph.ca (A.G.); ayyanath@uoguelph.ca (M.M.A.) \\ 2 Department of Horticulture, Damanhour University, Damanhour 22713, El-Beheira, Egypt \\ 3 Alson H. Smith Jr. Agricultural Research and Extension Center, School of Plant and Environmental Sciences, \\ Virginia Tech, Winchester, VA 22602, USA \\ * Correspondence: ssherif@vt.edu (S.M.S.); psaxena@uoguelph.ca (P.K.S.)
}

check for updates

Citation: Hezema, Y.S.; Shukla, M.R.; Goel, A.; Ayyanath, M.M.; Sherif,

S.M.; Saxena, P.K. Rootstocks

Overexpressing StNPR1 and

StDREB1 Improve Osmotic Stress Tolerance of Wild-Type Scion in Transgrafted Tobacco Plants. Int. J. Mol. Sci. 2021, 22, 8398. https:// doi.org/10.3390/ijms22168398

Academic Editor: Ricardo Aroca

Received: 23 June 2021

Accepted: 3 August 2021

Published: 5 August 2021

Publisher's Note: MDPI stays neutral with regard to jurisdictional claims in published maps and institutional affiliations.

Copyright: (c) 2021 by the authors. Licensee MDPI, Basel, Switzerland. This article is an open access article distributed under the terms and conditions of the Creative Commons Attribution (CC BY) license (https:// creativecommons.org/licenses/by/ $4.0 /)$.

\begin{abstract}
In grafted plants, the movement of long-distance signals from rootstocks can modulate the development and function of the scion. To understand the mechanisms by which tolerant rootstocks improve scion responses to osmotic stress (OS) conditions, mRNA transport of osmotic responsive genes (ORGs) was evaluated in a tomato/potato heterograft system. In this system, Solanum tuberosum was used as a rootstock and Solanum lycopersicum as a scion. We detected changes in the gene expression levels of 13 out of the 21 ORGs tested in the osmotically stressed plants; of these, only NPR1 transcripts were transported across the graft union under both normal and OS conditions. Importantly, OS increased the abundance of StNPR1 transcripts in the tomato scion. To examine mRNA mobility in transgrafted plants, StNPR1 and StDREB1 genes representing the mobile and non-mobile transcripts, respectively, were overexpressed in tobacco (Nicotiana tabacum). The evaluation of transgenic tobacco plants indicated that overexpression of these genes enhanced the growth and improved the physiological status of transgenic plants growing under OS conditions induced by $\mathrm{NaCl}$, mannitol and polyethylene glycol (PEG). We also found that transgenic tobacco rootstocks increased the OS tolerance of the WT-scion. Indeed, WT scions on transgenic rootstocks had higher ORGs transcript levels than their counterparts on non-transgenic rootstocks. However, neither StNPR1 nor StDREB1 transcripts were transported from the transgenic rootstock to the wild-type (WT) tobacco scion, suggesting that other long-distance signals downstream these transgenes could have moved across the graft union leading to OS tolerance. Overall, our results signify the importance of StNPR1 and StDREB1 as two anticipated candidates for the development of stress-resilient crops through transgrafting technology.
\end{abstract}

Keywords: transgrafting; mRNA transport; osmotic stress; ABA; StNPR1; StDREB1; ORGs; ROS

\section{Introduction}

Vascular tissues (i.e., phloem and xylem) extend throughout the whole plant, forming a continuous trafficking pathway that allows for long-distance communication. As part of this communication process, phloem and xylem can transport small molecules such as water, hormone, ions, amino acids, and photoassimilates [1-3]. In fact, large molecules like RNA and proteins can move not only intracellularly, but also over long distances, and some of these molecules can work as systemic signals in plants [4-10]. For example, the mobile florigen protein encoded by the flowering locus $t$ (FT) gene, which is a part of the signal that is involved in promoting flowering, is produced in the rootstock leaves and moves through the graft union to the growing points of the scion to promote flowering [6]. Besides, different types of RNA (mRNAs, miRNAs, and siRNAs) can be transported over 
long distances through the graft union, and these mobile RNAs can modulate several functions in the distant target tissue [5,9,11-13]. For instance, BEL1-like transcription factor (BEL5) mRNA can be transported over a long distance from the scion leaves to the rootstock to regulate tuber formation in potatoes by modulating genes that control growth and activating the sugar transport system to enhance assimilates influx and sink strength of young tubers $[4,14-16]$.

Osmotic stress (OS) is a major threat to sustainable crop production worldwide. Almost all abiotic stresses such as drought, salinity, heat, cold, and freezing induce OS [17-21]. OS is characterized by decreased turgor pressure and increased water loss, which causes severe damage to cell membranes, disrupts normal cellular activities, and finally results in plant death. As a tolerance mechanism, plants have evolved different strategies to avoid and mitigate OS [22-26]. At the molecular level, plants can increase their tolerance to OS by manipulating the expression of osmotic responsive genes (ORGs) $[24,27,28]$. These genes are involved in different physiological and biochemical processes such as plant hormone synthesis and signaling, cell expansion, lateral root formation, and stomatal closure [29-33]. An example of biochemical changes associated with abiotic stress is the induction of abscisic acid (ABA), a known stress hormone that serves several roles in plant growth and development [34]. One of the most important roles of $\mathrm{ABA}$ under abiotic stress is controlling stomatal closure to mitigate transpiration and water loss [35,36]. ABA also alleviates stress injury by promoting various stress-related genes that are involved in enhancing plant tolerance to stress [20]. Interestingly, $\mathrm{ABA}$ also acts as a long-distance signal that moves from the root to the shoot and vice versa through xylem and phloem [37-39].

Grafting has been used as a commercial plant propagation by merging two parts of different plants (the upper part is termed 'scion' and the lower part is termed 'rootstock'). Rootstocks can improve the tolerance of grafted plants to biotic stressors such as fire blight, fusarium wilt, phytophthora blight and root-knot nematodes in different plant species [40,41]. Rootstocks are also used to improve plant's tolerance to abiotic stresses, such heat, cold, salinity and drought stresses [41-43], and control the growth and yield of fruit crops [44]. Transgrafting is defined as grafting a wild-type scion to a genetically modified rootstock (or vice versa) to modulate certain aspects of the scion, including tolerance to biotic and abiotic stress [45]. At the commercial level, transgrafting is perceived as a more consumerfriendly technology for germplasm development compared with genetic transformation In essence, transgrafting can improve the qualitative and quantitative agricultural traits of the scion without integrating novel genetic materials in the scion tissues [3,46]. From a scientific perspective, transgrafting provides a useful tool for understanding how large molecules move over long distances and influence distant recipient tissues. In fact, transgrafting has been used to study the underlying mechanisms of the signals involved in dwarfing of tobacco, tomato, and apple plants [47-50]. In a study using a wild-tobacco scion grafted to a transgenic rootstock expressing the gai gene, gai transcripts were found in the scion. The translated product of the gai mRNA was also found in the scion of the semi-dwarf phenotype, which provides an explanation, at least partially, of how the dwarfing rootstock can decrease the size of the scion [49]. In a similar example, a non-transgenic apple scion grafted to a transgenic apple rootstock expressing rolB (rooting locus B) has shown reduced growth and flowering with no effects on fruit quality [44]. The aforementioned study also found that rolB transcripts were not detected in non-transgenic apple scion grafted on transgenic apple rootstock. In addition, Prunus persica C-repeat binding factor $(P p C B F)$ involved in cold and drought stress responses reduced scion growth and delayed flowering of the 'Royal Gala' wild-type scion when overexpressed in M26 apple rootstock. However, P $p C B F 1$ mRNA was not detected in the scion tissues [46].

Genetically modified rootstocks have proven to be efficient for modulating wildtype scion growth $[46,49,50]$; however, it remains largely unknown how rootstocks can modulate scions' responses, especially under OS. To the best of our knowledge, there are no previous studies that examined the transport of ORG transcripts over long distances in osmotically stressed grafted plants. Identification of highly regulated ORGs that are 
involved in promoting OS tolerance in plants can be used to develop tolerant transgenic rootstocks. In the present study, we hypothesized that mRNA of some ORGs could move long distances over graft junctions from the rootstock to the scion tissues under OS conditions. We also hypothesized that transgrafted plants overexpressing mobile ORGs in the rootstock could increase the tolerance of WT scions to OS. Therefore, in the present study we aimed to identify ORGs with mobile mRNA, and investigate the physiological, biochemical and molecular mechanisms underlying the imparted tolerance, if any, from transgenic rootstocks to WT scions in transgrafted plants under OS. To this end, a homograft of potato/potato was used to initially identify ORGs genes whose expression was highly regulated under OS conditions. A heterograft composed of tomato as the recipient scion and potato as the donor rootstock was then used as a model system to assess the translocation of ORGs mRNAs from the rootstock to the scion using qRT-PCR. Two genes involved in two different signaling pathways (StNPR1 and StDREB1) were transformed into tobacco plants. Transgrafts composed of tobacco plants overexpressing StNPR1 and StDREB1 as rootstocks and wild-type tobacco (WT) as scions were then used to explore the effects of tolerant transgenic rootstocks on physiological responses, ABA content and gene expression in WT scion under normal and OS conditions.

\section{Results}

\subsection{Expression Profiles of ORGs in the Homografted Potato Plants}

To investigate the expression pattern of ORGs in response to OS in the homografted potato $(\mathrm{P} / \mathrm{P})$ plants, a total of 21 highly regulated ORGs [24,32,51] involved in different processes were tested. The results of the qRT-PCR analysis showed differential expression of the selected genes under OS. As shown in Figure 1, compared to the control plants (C-P/P), the level of dehydration responsive element binding (DREB) transcripts increased by 2and 27 -fold in the scion of the potato $6 \mathrm{~h}$ and $24 \mathrm{~h}$, respectively, after PEG treatment. There was also a significant up-regulation (nearly 200 -fold) in the expression of the responsive to desiccation (RD29) gene after $6 \mathrm{~h}$ and $24 \mathrm{~h}$ compared to the control (Figure 1). The results also showed a significant 2-fold increase in early responsive to dehydration 7 transcript levels (ERD7) at $24 \mathrm{~h}$. On the other hand, transcript levels of the abscisic acid insensitive 2 (ABI2) gene, a negative regulator of abscisic acid (ABA), showed a non-significant reduction at $6 \mathrm{~h}$ of PEG treatments, then increased again matching the control at $24 \mathrm{~h}$ (Figure 1). There were no changes in the expression levels of $M Y C 2$ and MYB2. However, MYB74 gene expression levels were significantly up-regulated by nearly 13- and 5-fold at $6 \mathrm{~h}$ and $24 \mathrm{~h}$, respectively, relative to the control. A 6- and a 24-fold increase in transcript levels was also detected for the non-expressor of Pathogenesis-Related (PR) genes 1 (NPR1) at $6 \mathrm{~h}$ and $24 \mathrm{~h}$, respectively (Figure 1). There was also a significant increase in the expression levels of Alcohol dehydrogenase 1 (ADH1) by 4-fold at $6 \mathrm{~h}$ (Figure 1). The expression levels of UDP-sugar glycosyltransferases (UGT) were up-regulated by 3- and 12-fold at $6 \mathrm{~h}$ and $24 \mathrm{~h}$, respectively. Additionally, transcript levels of salt tolerance zinc finger (STZ) increased significantly by 3 -fold at $24 \mathrm{~h}$ (Figure 1). On the other hand, there were no significant changes in the expression levels of ATPase, LIP2, AFP4, and SNRK compared to the control either at $6 \mathrm{~h}$ or $24 \mathrm{~h}$ (Figure 1). The gene expression levels of six heat shock proteins $(H S P)$ were also determined. HSP17 and HSP26,5P showed a similar pattern in their responses, and significantly increased by 80 - and 86.6 -fold, respectively, at $24 \mathrm{~h}$ only. On the other hand, no changes were observed in the abundance of HSP21 as a result of the stress treatment (Figure 1). HSP18-1 showed a significant 20-fold increase at $24 \mathrm{~h}$ compared to the control (Figure 1). There was also a significant increase of 13-fold in HSP17-6C expression at $6 \mathrm{~h}$, after which the levels decreased at $24 \mathrm{~h}$ and were similar to the expression levels in the control (Figure 1). HSP17-6A demonstrated a significant up-regulation of 12- and 20 -fold at $6 \mathrm{~h}$ and $24 \mathrm{~h}$, respectively (Figure 1). 


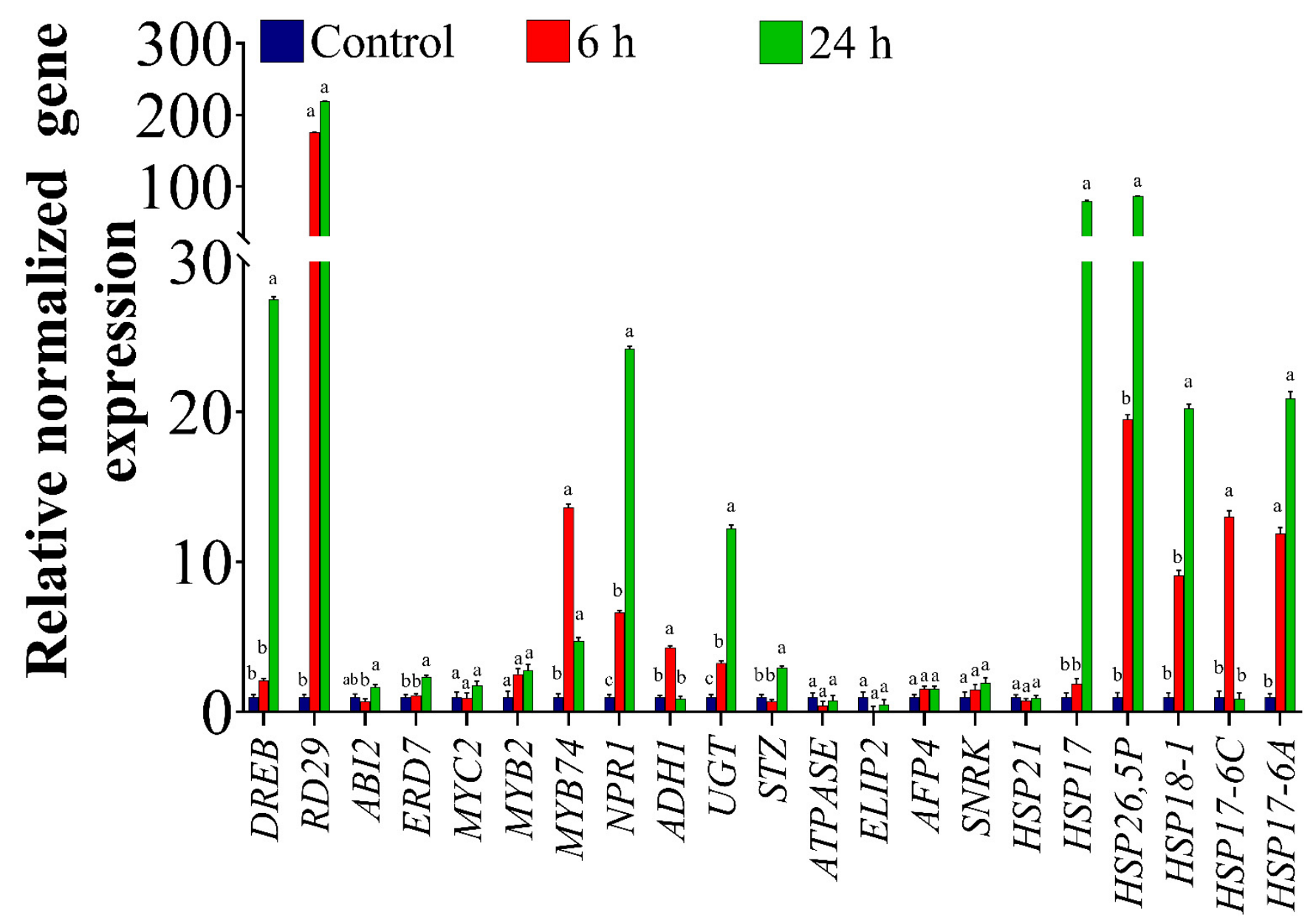

Figure 1. Expression of ORGs genes in homografted potatoes (Solanum tuberosum), assessed by qRT-PCR. Plants were osmotically stressed by watering with $30 \%$ PEG four weeks after graft establishment. Tissues located $5 \mathrm{~cm}$ above the graft union were collected from untreated plants (control) and PEG-treated plants at $6 \mathrm{~h}$ and $24 \mathrm{~h}$ of treatment. The bars show the normalized relative expression of potato ORGs. The gene expression values were calculated relative to homografted potato control $(\mathrm{P} / \mathrm{P})$ and normalized to TIP, an internal control. The bars represent the means $\pm \mathrm{SEM}$ of three biological replicates. Different letters in the graph indicate significant differences $(p<0.05)$ in relative gene expression between treatments after Tukey's test.

\subsection{The Movement of ORGs Transcripts across the Graft Union under Osmotic Stress Conditions}

A strategy based on the grafting of two different plant species was used to identify the genes with mobile transcripts. A heterograft system, in which tomato (Solanum lycopersicum 'Beefsteak') was used as a scion and potato (Solanum tuberosum 'Gold rush') as a rootstock, was established to identify the root-to-shoot long-distance movement of mRNAs under normal and osmotic conditions using potato-specific primers. As shown in Supplementary Figure S1, the three potato-specific housekeeping genes (StGTP, StTIP, and StClathrin) had no detectable expression in scion tissues, indicating their inability to move from the rootstock to scion. Another set of primers (GTP, TIP, and Clathrin) was designed from conserved nucleotide sequences in tomato and potato to be used for gene expression studies in the heterografts. Of these, only TIP showed a gene expression that was stable in potato and tomato under all the tested conditions (Supplementary Figure S1) and was therefore used to normalize the relative gene expression data in both potato and tomato.

mRNA mobility of osmotic-related genes was examined by qRT-PCR using primers that were specific to potato (Supplementary Table S1). The abundance of potato transcripts in the tomato scion examined $6 \mathrm{~h}$ after stress induction is shown as a heatmap in Supplementary Figure S2. In general, all ORGs have been detected in the homografted potato 
$(\mathrm{P} / \mathrm{P})$ under control and stress conditions, whereas no transcripts were detected in the homografted tomato (T/T) (Supplementary Figure S2), which confirms the high specificity and reliability of the chosen potato primers. The results also indicated that all, except one of the tested ORGs, have non-mobile transcripts under normal or stress conditions. Only the mRNA of StNPR1 from the potato rootstock was detected in the tomato scion under normal and OS conditions. The movement through the graft union of different mRNAs encoding the NPR family was then assessed to explore whether the members of the same gene family share the same mRNA mobility properties. The results as presented in Supplementary Figure S2 showed that all the members of the NPR family, except NPR1 were found to be non-mobile under both normal and stress conditions. This result shows that different members of the same gene family may not follow the same pattern in their transport.

It is worth noting that although StNPR1 was detected under both normal and stress conditions, the level of StNPR1 expression was significantly higher at $24 \mathrm{~h}$ in stressed tomato/potato heterografts $(\mathrm{T} / \mathrm{P})$ compared to the heterograft control $(\mathrm{T} / \mathrm{P})$ (Figure 2a). Compared to the expression of StNPR1 in the potato homograft control (P/P) (Figure 2a), the StNPR1 gene expression levels in tomato/potato heterograft $(\mathrm{T} / \mathrm{P})$ showed 0.01 -fold, 0.17 -fold, and 0.55 -fold in control, and at $6 \mathrm{~h}$ and $24 \mathrm{~h}$, respectively. These results were further confirmed by semi-quantitative RT-PCR, in which primers amplifying a larger NPR1 fragment (501 bp) were used (Figure $2 b$ ).

a

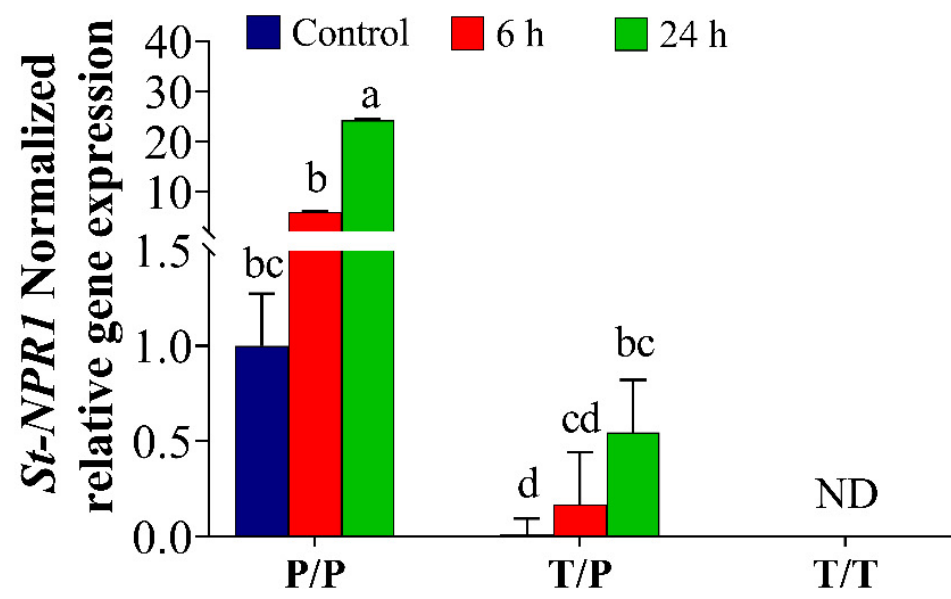

b

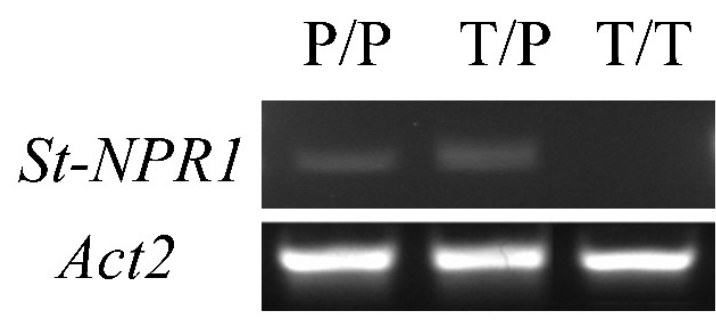

Figure 2. Quantitative and semi-quantitative expression of StNPR1 in tomato scion. The plants were stressed by watering with $30 \%$ PEG. A tissue sampled $5 \mathrm{~cm}$ above the graft union at $6 \mathrm{~h}$ and $24 \mathrm{~h}$ after PEG treatment was used for RNA extractions and gene expression studies. (a) The normalized relative gene expression of StNPR1. The bars represent the means \pm SEM of three biological replicates. The relative expression of potato genes was calculated relative to the homografted potato control $(\mathrm{P} / \mathrm{P})$ and normalized to TIP. Different letters in the graph indicate significant differences $(p \leq 0.05)$ in relative gene expression between treatments after Tukey's test, ND means no detected transcripts. (b) Semi-quantitative PCR results show the movement of StNPR1 transcripts from the potato rootstock into the tomato scion using potato-specific primers. Homografted potato $(\mathrm{P} / \mathrm{P})$, heterografted tomato scion/potato rootstock $(\mathrm{T} / \mathrm{P})$, and homografted tomato (T/T). Actin2 was used as a reference gene.

\subsection{Potato Rootstock Increased ABA Content in Tomato Scion}

ABA content was determined in the scion leaves of $\mathrm{T} / \mathrm{T}, \mathrm{P} / \mathrm{P}, \mathrm{T} / \mathrm{P}$ plants under control and OS conditions (Figure 3). Within the same treatment, a marked increase of $53 \%$, $57 \%$, and $72 \%$ was observed in the leaves of $\mathrm{T} / \mathrm{T}, \mathrm{P} / \mathrm{P}$ and $\mathrm{T} / \mathrm{P}$, respectively, $24 \mathrm{~h}$ after exposure to $30 \%$ PEG. ABA level was $33 \%$ higher in the leaves of $\mathrm{P} / \mathrm{P}$ scion relative to $\mathrm{T} / \mathrm{T}$ under control conditions; however, no significant differences were observed between scions of $\mathrm{T} / \mathrm{T}$ and $\mathrm{T} / \mathrm{P}$ plants under control conditions. ABA content also showed $44 \%$ 
and $32.8 \%$ increase in the leaves of $\mathrm{P} / \mathrm{P}$ and $\mathrm{T} / \mathrm{P}$, respectively, compared to $\mathrm{T} / \mathrm{T}$ under $\mathrm{OS}$, suggesting that potato generally has higher ABA content than tomato under normal and stress conditions (Figure 3).

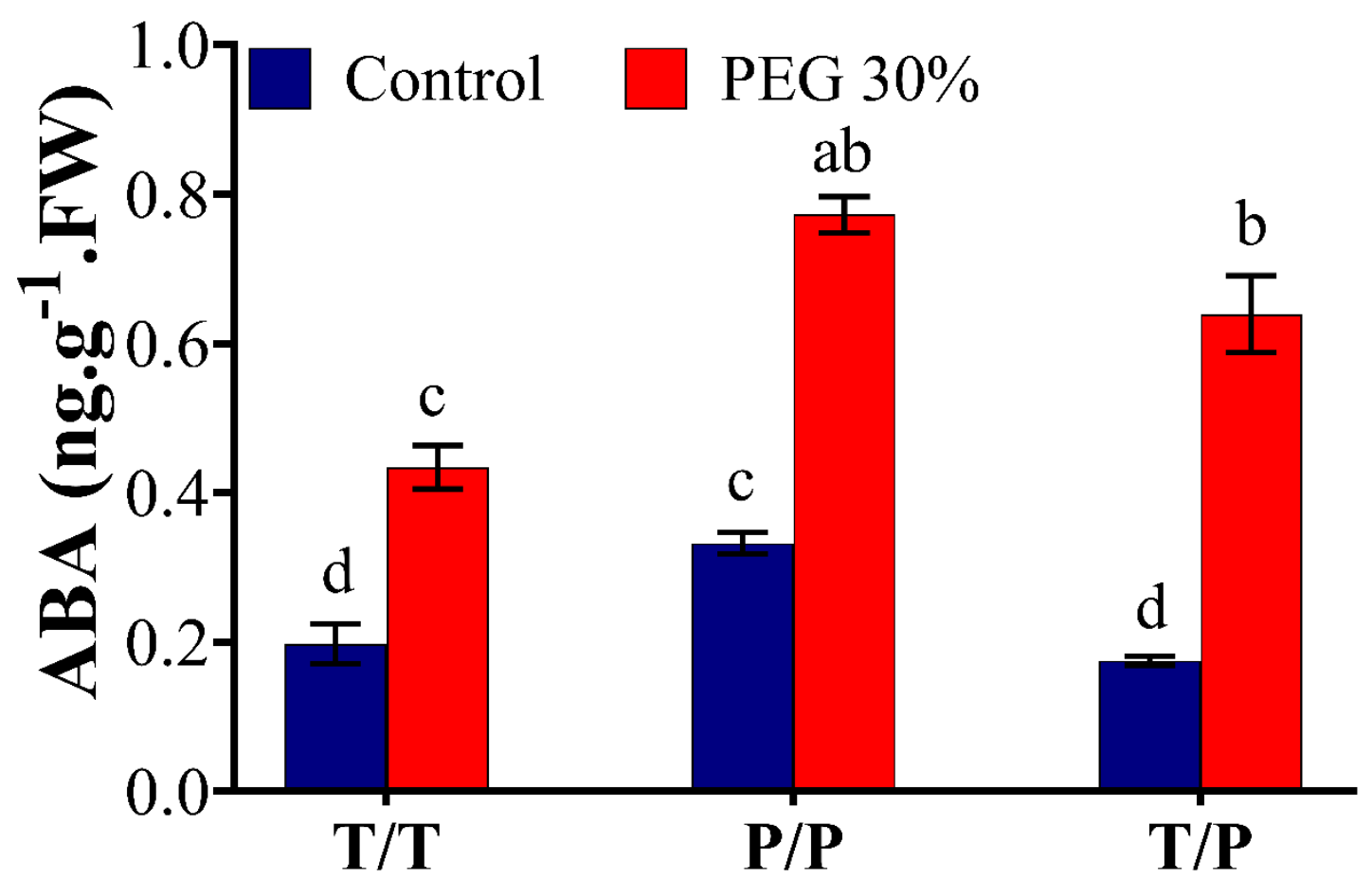

Figure 3. Quantification of ABA in potato and tomato plants. The homografted and heterografted plants were osmotically stressed by watering with 30\% PEG. Leaves were collected at $24 \mathrm{~h}$ from the scion of homografted tomato (T/T), homografted potato $(\mathrm{P} / \mathrm{P})$ and heterografted $(\mathrm{T} / \mathrm{P})$ growing under untreated (control) and osmotic stress conditions. The bars represent the means \pm SEM of three biological replicates. Different letters in each column indicate significant differences $(p \leq 0.05)$ between treatments after Tukey's test.

\subsection{Molecular Analyses of Transgenic Tobacco Plants}

Two pCambia1301plant expression vectors harboring the coding regions of StNPR1 and StDREB1 genes under the control of the CaMV35S promoter were constructed, as illustrated in Figure 4a. These vectors were designed to express GUS as a reporter gene attached to both transgenes in the same open reading frame (ORF) to facilitate tracking gene transport from transgenic rootstocks to non-transgenic, wild type (WT), scion. Two lines overexpressing StNPR1 (N2 and N4), three lines overexpressing StDREB1 (D1, D7 and D11), one line overexpressing GUS only (G3) and wild type (WT) tobacco plants were screened by semi-quantitative PCR using GUS, StNPR1 and StDREB1 primers. Figure $4 \mathrm{~b}$ confirmed the presence of the transgenes in the genomic DNA of selected $\mathrm{F}_{1}$ lines using NtActin as an internal reference gene. The relative gene expression analysis using quantitative real-time PCR (qRT-PCR) also revealed high transcript levels of GUS in all the transgenic lines G3, N2, D7 and D11, but not in the WT (Figure 4c). 


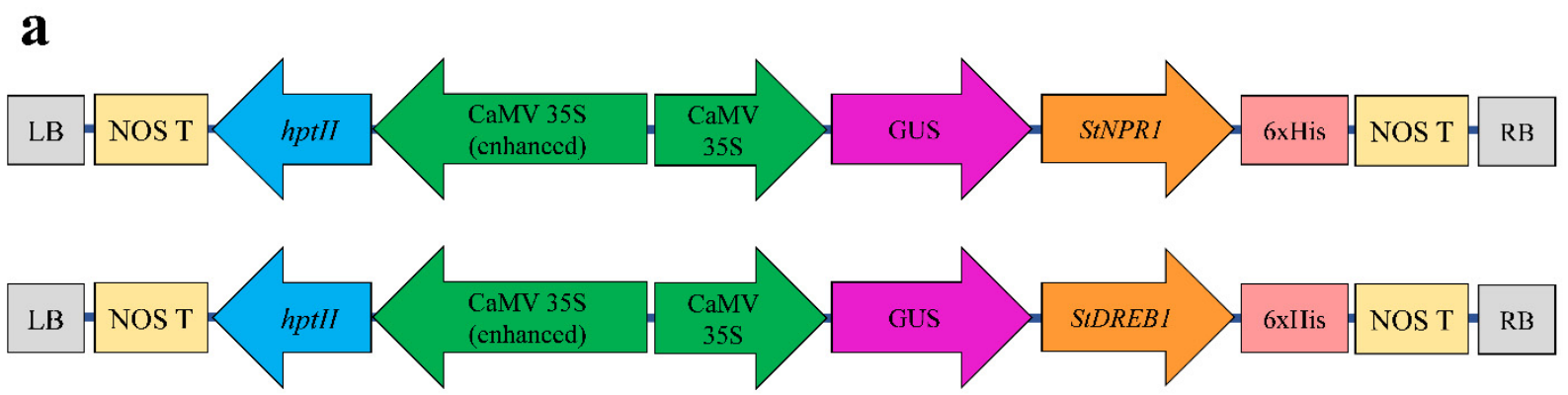

b

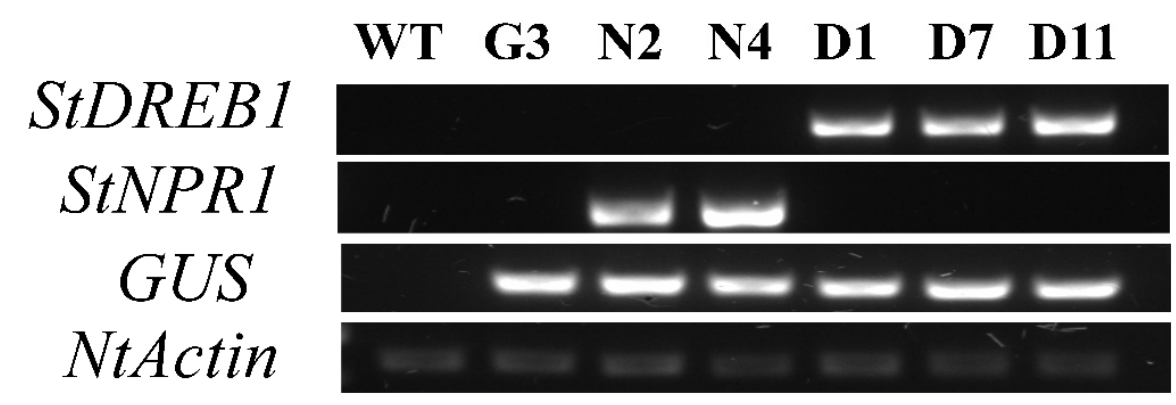

c

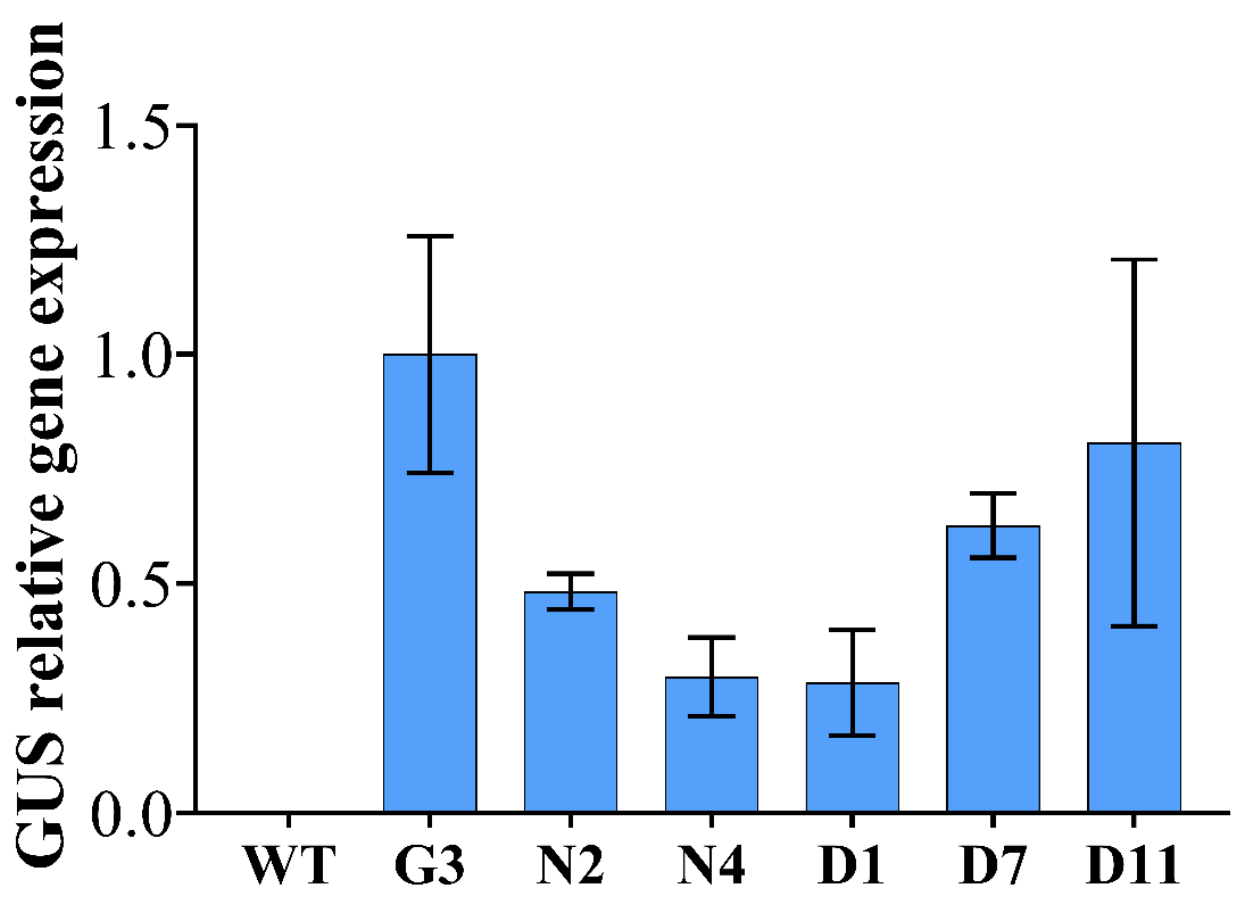

Figure 4. Overexpression of tomato StNPR1 and StDREB genes in tobacco. (a) Schematic map of genetic constructs expressing GUS-StNPR1- and GUS-StDREB1 chimeric proteins under the control of the CaMV35S promoter. (b) Confirmation of transgenes in the genomic DNA by semi-quantitative PCR amplification of GUS, StNPR1 and StDREB1 transcripts in WT, and transgenic lines of GUS only (G3) StNPR1 (N2 and N4) and StDREB1 (D1, D7 and D1). Tobacco Nt-Actin was used as an internal gene control. (c) Relative GUS expression in the transgenic lines using qRT-PCR. No significant differences were observed among the transgenic lines at $p \leq 0.05$ according to Tukey test. 


\subsection{Overexpression of StNPR1 and StDREB1 Confers Enhanced Growth under Stress Conditions}

Leaf disc senescence assay was performed to evaluate the tolerance of $F_{1}$ transgenic lines to salinity induced by $100 \mathrm{mM} \mathrm{NaCl}$ and OS induced by $200 \mathrm{mM}$ mannitol and $10 \%$ PEG for nine days (Figure 5a). In general, the results showed induced damage in leaf discs under various stress treatments; however, the transgenic lines N2, N4, D1, D7 and D11 showed less injuries compared to control plants (WT and G3) under salt and OS conditions. Along the same vein, transgenic lines (N2, N4, D1, D7 and D11) showed an average of $13 \%, 58 \%$ and $43 \%$ lower electrolyte leakage (EL) under stress induced by $\mathrm{NaCl}$, mannitol and PEG, respectively, compared to the average of control plants (WT and G3) (Figure 5c). This was also consistent with the cell viability (CV) data, where control plants showed a reduction of $36.4 \%, 23.2 \%$ and $17 \%$ in cell viability compared to the transgenic lines exposed to $\mathrm{NaCl}$, mannitol and PEG, respectively (Figure $5 \mathrm{~d}$ ). However, no significant differences were observed in N4 exposed to mannitol and N4 and D1 exposed to PEG (Figure 5d). Another indicator of transgenic plants' tolerance to OS was revealed by the measurement of leaf's chlorophyll content. As shown in Figure 5e, transgenic lines, mainly N2, D7 and D11, showed $44.4 \%, 25.6 \%$ and $25.5 \%$ higher chlorophyll content under stress induced by $\mathrm{NaCl}$, mannitol and PEG, respectively, compared to WT. Overall, these results illustrated that tobacco plants overexpressing StNPR1 and StDREB1 had a better ability to tolerate salt and OS.
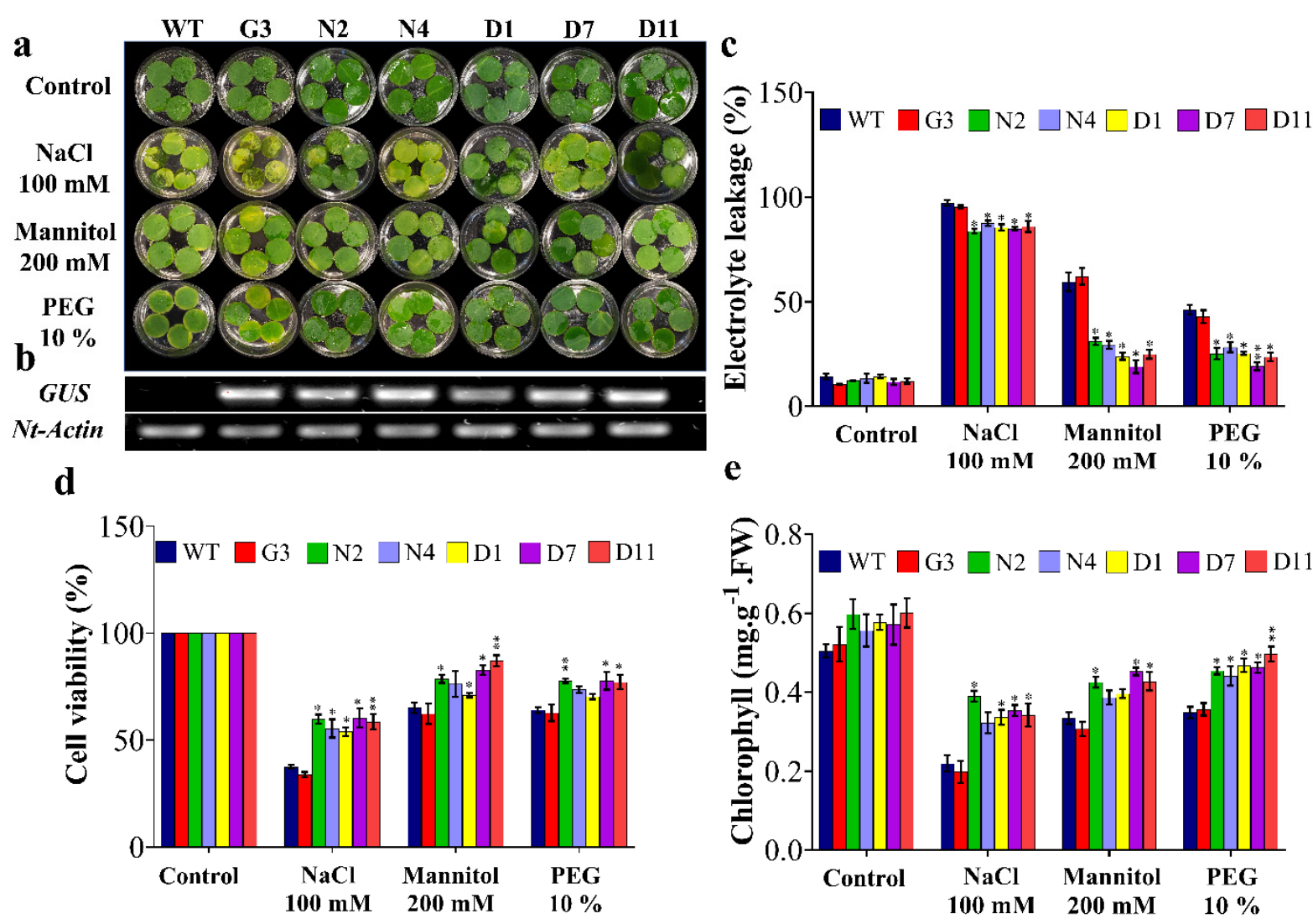

Figure 5. Leaf disc senescence assay and physiological analyses of transgenic lines under stress conditions. (a) The leaf discs of $\mathrm{F}_{1}$ transgenic lines and WT plants were incubated under $\mathrm{NaCl}(100 \mathrm{mM})$, mannitol $(200 \mathrm{mM})$ and PEG (10\%) stresses. Control refers to leaf discs at 0 days; stress treatments show leaf discs after nine days of incubation. (b) Overexpression of GUS in transgenic lines compared to wild-type control plants. (c) Estimation of the electrolyte leakage percentage, (d) cell viability, (e) total chlorophyll. The bars represent mean values \pm SEM of three biological replicates (four plants each). Asterisk(s) indicate(s) significant differences between the means of wild type (WT) and transgenic line of each treatment group at ${ }^{*}<0.05,{ }^{* *} p<0.01$ according to Dunnett test. 
Based on leaf disc assay results (Figure 5), the $\mathrm{F}_{2}$ transgenic lines (G3, N2 and D7) and WT were selected for further morphological and biochemical analyses. The seed germination of G3, N2 and D7 transgenic lines was checked on MS + vitamins medium supplemented with $20 \mu \mathrm{g} / \mathrm{mL}$ hygromycin for two weeks, and the surviving seedlings were selected for further characterization. The surviving seedlings were then sub-cultured for four weeks on MS media supplemented with $100 \mathrm{mM} \mathrm{NaCl}, 200 \mathrm{mM}, 10 \%$ PEG and MS + vitamins for WT plants (Figure 6a). Figure $6 \mathrm{~b}$ shows a significant improvement of shoot length in N2 and D7 under salt and OS compared to control group (WT and G3) grown under the same conditions. Indeed, N2 showed 34.1\%, 25\% and 40\% higher shoot length under $\mathrm{NaCl}$, mannitol and PEG stresses, respectively. Similarly, D7 demonstrated $44.1 \%$, $29.3 \%$ and $27.6 \%$ higher shoot length under $\mathrm{NaCl}$, mannitol and PEG stresses, respectively, compared to control plants. As far as root growth is concerned, our data showed that root length was significantly higher in N2 and D7 under induced OS by mannitol and PEG stresses, respectively (Figure 6c). Additionally, we found that N2 expressed 34\%, 28.6\% and $24.9 \%$ higher fresh weight under $\mathrm{NaCl}$, mannitol and PEG stresses, respectively, compared to the control plants. Similarly, D7 showed higher fresh weight by $33 \%, 36.8 \%, 47.2 \%$ and $43.7 \%$ under control, $\mathrm{NaCl}$, mannitol and PEG conditions, respectively, compared to WT (Figure 6d). In the same manner, dry weight in N2 seedlings was $40.7 \%, 35 \%$ and $25.3 \%$ higher under $\mathrm{NaCl}$, mannitol and PEG conditions, respectively (Figure 6e); while D7 was $48.3 \%, 50.5 \%$ and $42.9 \%$ higher under the same conditions, respectively. Moreover, root weight was significantly higher in D7 plants by $33.7 \%, 30 \%, 45.8$ and $35.2 \%$ growing under control, NaCl, mannitol and PEG conditions, respectively, while N2 plants showed $22.8 \%$ higher root weight compared to control plants when exposed $200 \mathrm{mM}$ mannitol (Figure 6f). Among salt and OS treatments, N2 and D7 exhibited better growth under OS than under salt stress. The selected transgenic lines were generally healthier and showed better growth parameters under salt and OS than WT and G3.

\subsection{Transgenic Rootstocks Improved the Growth of WT Scion in Transgrafted Tobacco Plants}

$\mathrm{N} 2$ and D7 overexpressing StNPR1 and StDREB1, respectively, were used as rootstocks to study the effect of the tolerant transgenic rootstocks on the WT scions in transgrafted tobacco plants (Figure 7a) exposed to 10\% PEG. We initially examined the transport of transcripts of StNPR1 and StDREB1 from the corresponding transgenic rootstocks to the non-transgenic WT, scions by semi-quantitative PCR. We found that the transcripts of neither StNPR1 nor StDREB1 were detected in WT-scion of WT/N2 or WT/D7 transgrafted treatments (Figure $7 \mathrm{~b}$ ). Figure 8a,b shows the morphological changes in seven groups of grafted plants after exposure to $10 \%$ PEG for 0 day (control), 9 and 12 days. These groups represent homo- and heterografts of WT and transgenic plants, expressed as scion/rootstock. For instance, N2/N2 refers to a homograft of transgenic N2 plants, whereas WT/N2 refers to a heterograft of WT scion on N2 rootstock. The significant changes in physiological parameters between transgrafts and WT/WT appeared in samples collected at 9 and 12 days only. All the seven grafting treatments conferred similar responses under control conditions. In general, WT/WT, G3/G3 and WT/G3 plants showed comparable responses under OS conditions as indicated by relative water content (RWC), EL, CV and total chlorophyll content (Figure 8c-f). Similarly, N2/N2, D7/D7, WT/N2, and WT/D7 plants exhibited comparable responses after exposure to $10 \%$ PEG (Figure 8c-f). The use of tolerant transgenic rootstocks (N2 and D7) improved physiological parameters of WT scion in transgrafted tobacco (WT/N2 and WT/D7) compared to WT/WT under OS. Membrane injury measured by EL was lower in the scion of N2/N2, D7/D7, WT/N2 and WT/D7 than control plants under stress conditions at 9 and 12 days (Figure 8c). Furthermore, transgrafted plants showed significantly higher RWC and CV than the control group (WT/WT, G3/G3 and WT/G3) at 9 and 12 days after being subjected to OS (Figure 8d,e). Total chlorophyll content was also significantly higher in transgrafted tobacco compared to control plants at 12 days of stress treatment (Figure 8f). The cellular hydrogen peroxides $\left(\mathrm{H}_{2} \mathrm{O}_{2}\right)$ content indicated by the DAP staining or the titanium chloride 
method showed more accumulation of $\mathrm{H}_{2} \mathrm{O}_{2}$ in the leaves of the control plants compared to N2/N2, WT/N2, D7/D7 and WT/D7 under OS conditions (Figure 9). The results of EL, RWC, CV, chlorophyll content and $\mathrm{H}_{2} \mathrm{O}_{2}$ content provided evidence that using tolerant transgenic rootstocks overexpressing StNPR1 and StDREB1 could improve the growth of WT-scion compared to WT/WT growing under OS conditions.
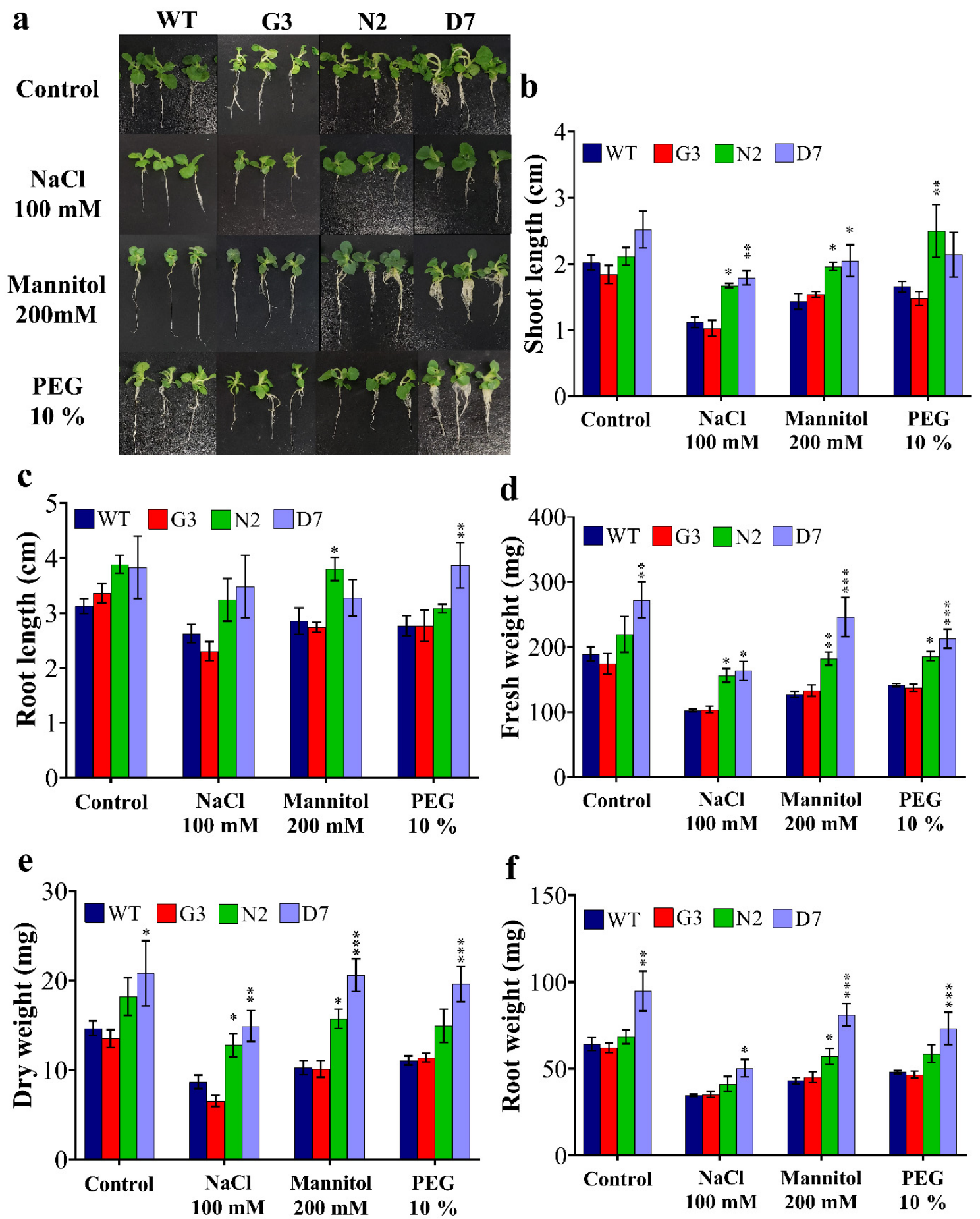

Figure 6. Morphology and growth characteristics of WT and transgenic lines as affected by different stress conditions. (a) Fourteen-days seedlings from WT and transgenic lines were grown in vitro for four weeks under control, $100 \mathrm{mM} \mathrm{NaCl}$, $200 \mathrm{mM}$ mannitol and 10\% PEG. (b) Shoot length, (c) root length, (d) fresh weight, (e) dry weight and (f) root fresh weight. The bars represent mean values \pm SEM of three biological replicates (four plants each). Asterisk(s) indicate(s) significant differences between the means of wild type (WT) and transgenic line of each treatment group at ${ }^{*} p<0.05,{ }^{* *} p<0.01$, *** $p<0.001$ according to Dunnett test. 
$\mathbf{a}$

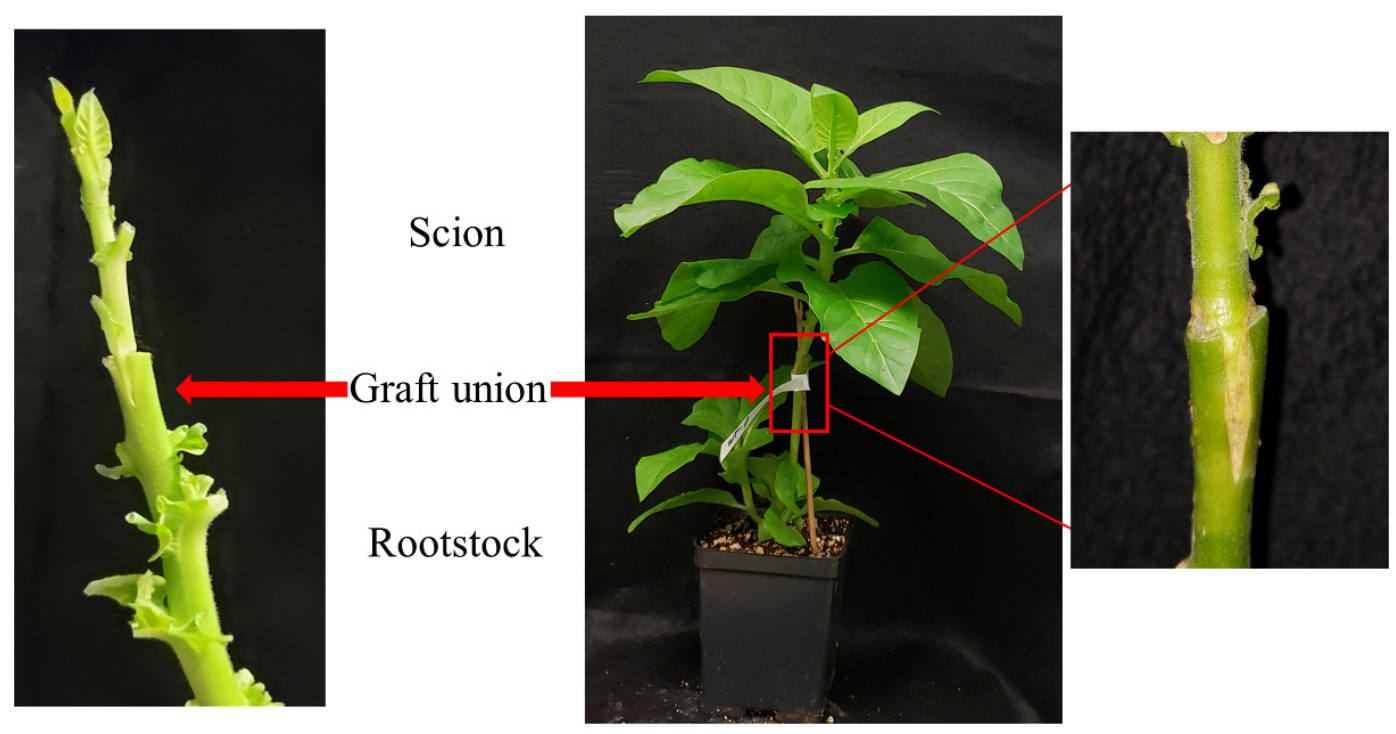

$\mathbf{b}$

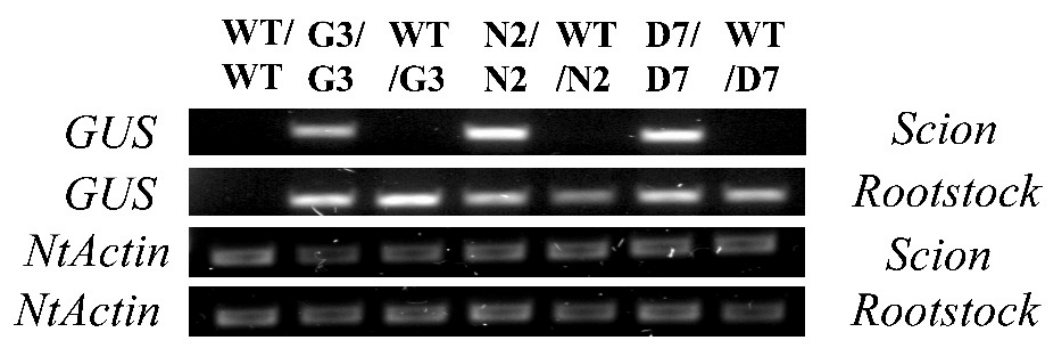

Figure 7. Analysis of transgrafted tobacco plants under osmotic stress conditions. (a) Wedge grafting and graft union four weeks from grafting. (b) Semi-quantitative PCR amplification of GUS in the scion of various graft union; WT/WT, G3/G3, WT/G3, N2/N2, WT/N2, D7/D7 and WT/D7. NtActin was used as an internal gene control.

\subsection{Evaluation of ABA Content in Transgrafted Tobacco Plants Growing under Osmotic Stress}

We determined the amount of abscisic acid (ABA) at 0,6 and 12 days of OS treatment (Figure 10) to evaluate whether ABA level in the scion could be changed in relation to the OS as well as the rootstock's level of ABA. In general, ABA content was not detectable at zero-day. However, at 12 days of exposure to 10\% PEG, ABA level significantly increased in WT/WT, G3/G3 and WT/G3 by $68 \%, 83 \%$ and $73 \%$, respectively, compared to its level at six days. In addition, N2/N2, WT/N2, D7/D7 and WT/D7 showed an increase of 65\%, $45 \%, 58 \%$ and $53 \%$, respectively, but such increase was not statistically significant. When compared to WT/WT, ABA level at 12 days in N2/N2, WT/N2, D7/D7 and WT/D7 were lower by $48.7 \%, 28 \%, 53.7 \%$ and $42.6 \%$, respectively. 
a

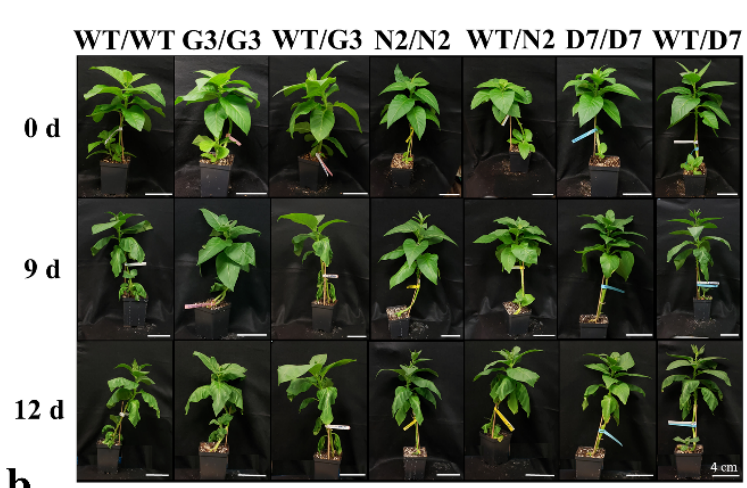

b

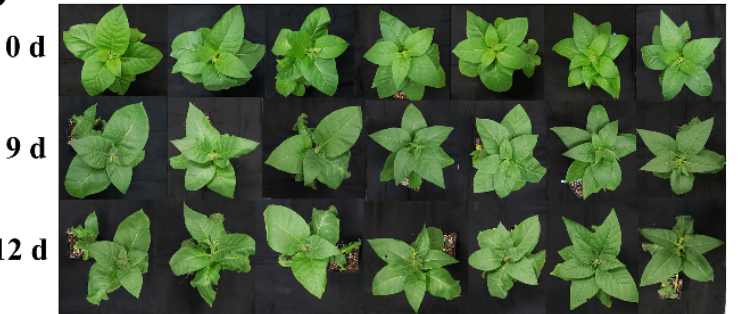

c

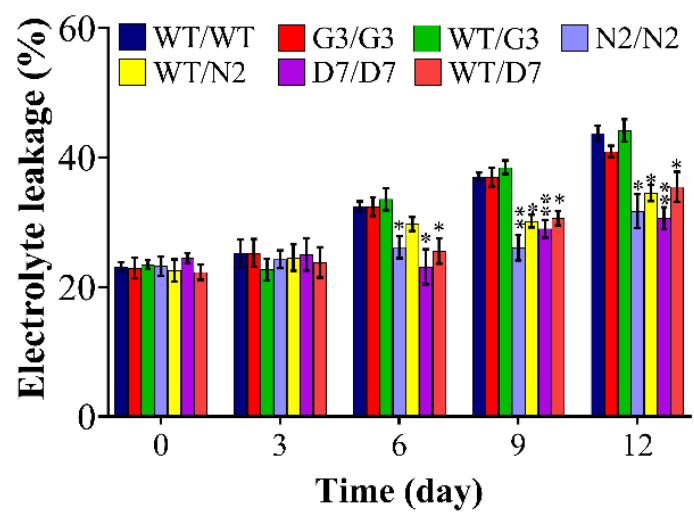

d

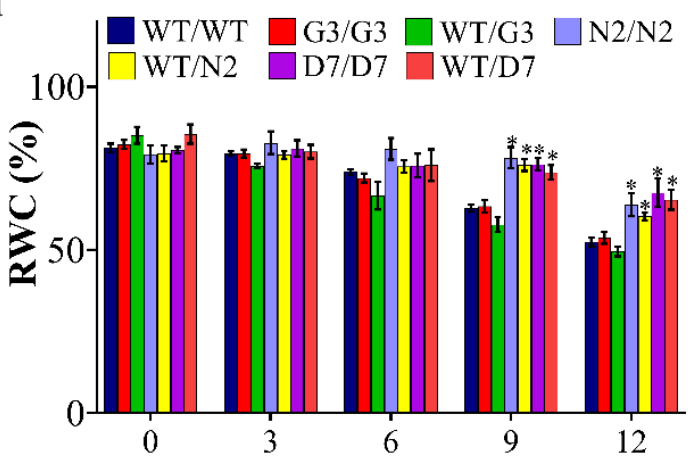

e

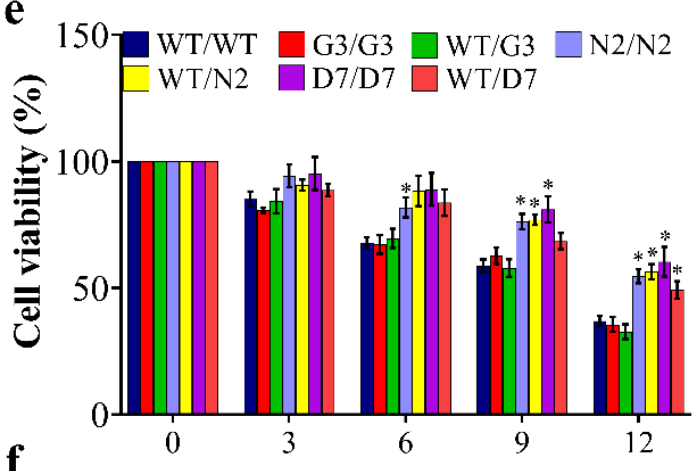

f

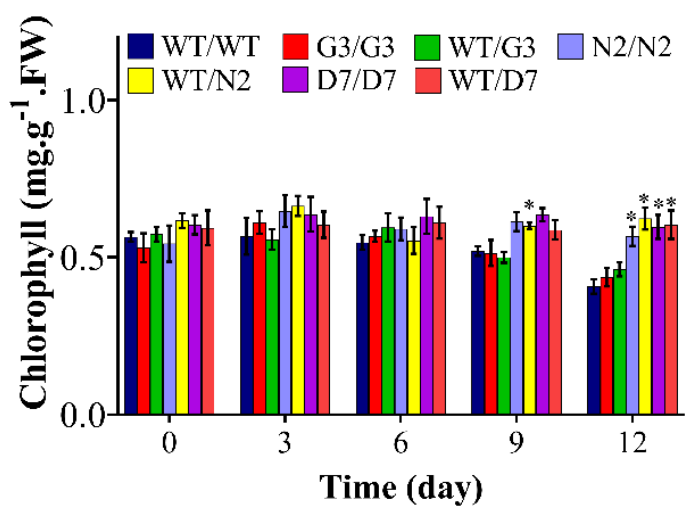

Figure 8. Physiological analysis of transgrafted tobacco plants under osmotic stress conditions. Comparison of wild-type homografted and transgrafted plants at 0, 3, 6, 9 and 12 days of exposing to PEG 10\%; WT/WT, G3/G3, WT/G3, N2/N2, WT/N2, D7/D7 and WT/D7 are grafting combinations. $(\mathbf{a}, \mathbf{b})$ Tobacco transgrafted plants response after 0,9 and 12 days of PEG treatment. (c) Electrolyte leakage, (d) relative water content (RWC), (e) cell viability, (f) chlorophyll content of homografts and transgrafts exposed to osmotic stress (10\% PEG). The bars represent mean values \pm SEM of three biological replicates (four plants each). Asterisk(s) indicate(s) significant differences between the means of wild type (WT/WT) and transgrafts of each treatment group at ${ }^{*} p<0.05,{ }^{* *} p<0.01$ according to Dunnett test. 
a

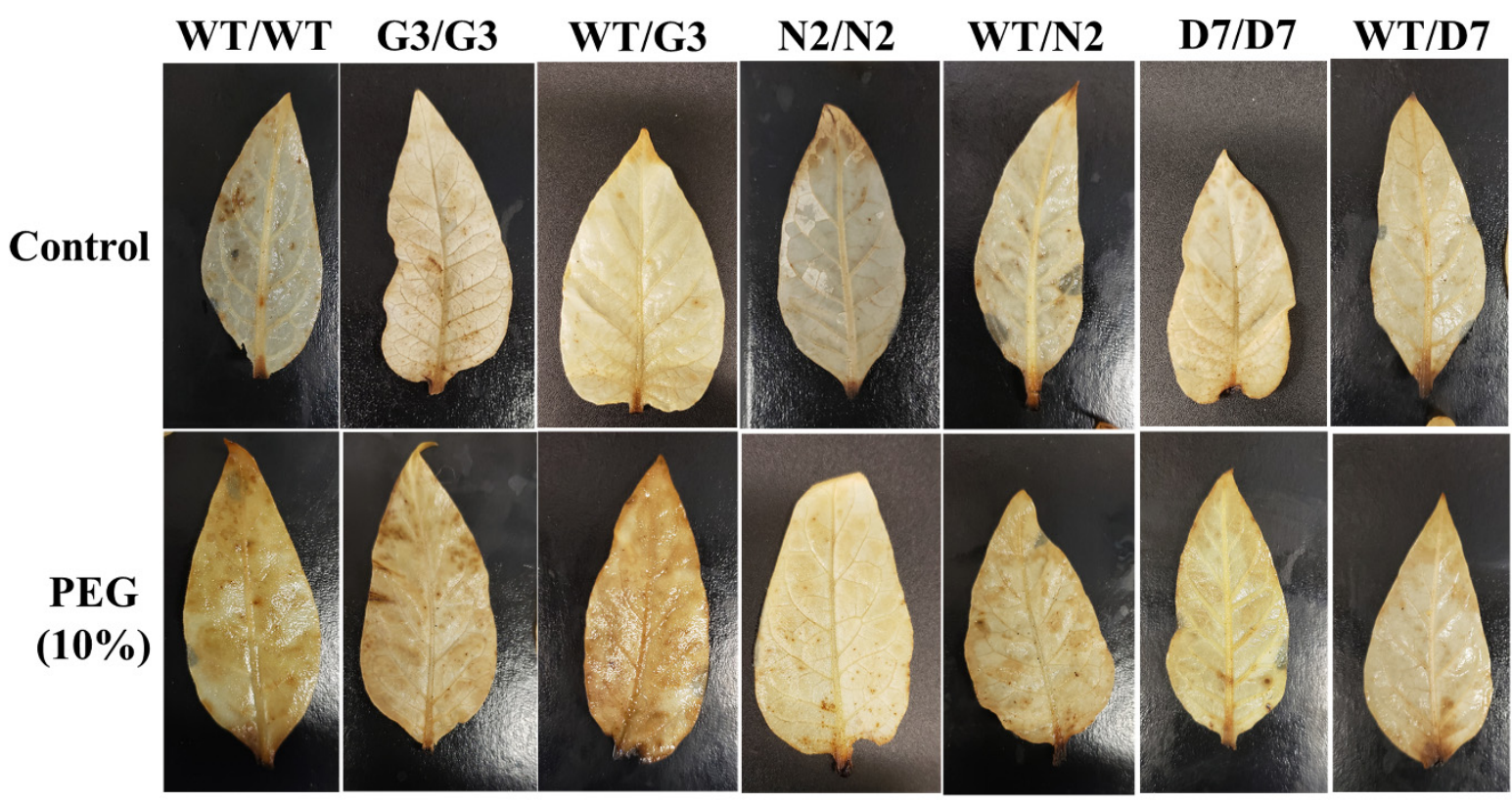

b

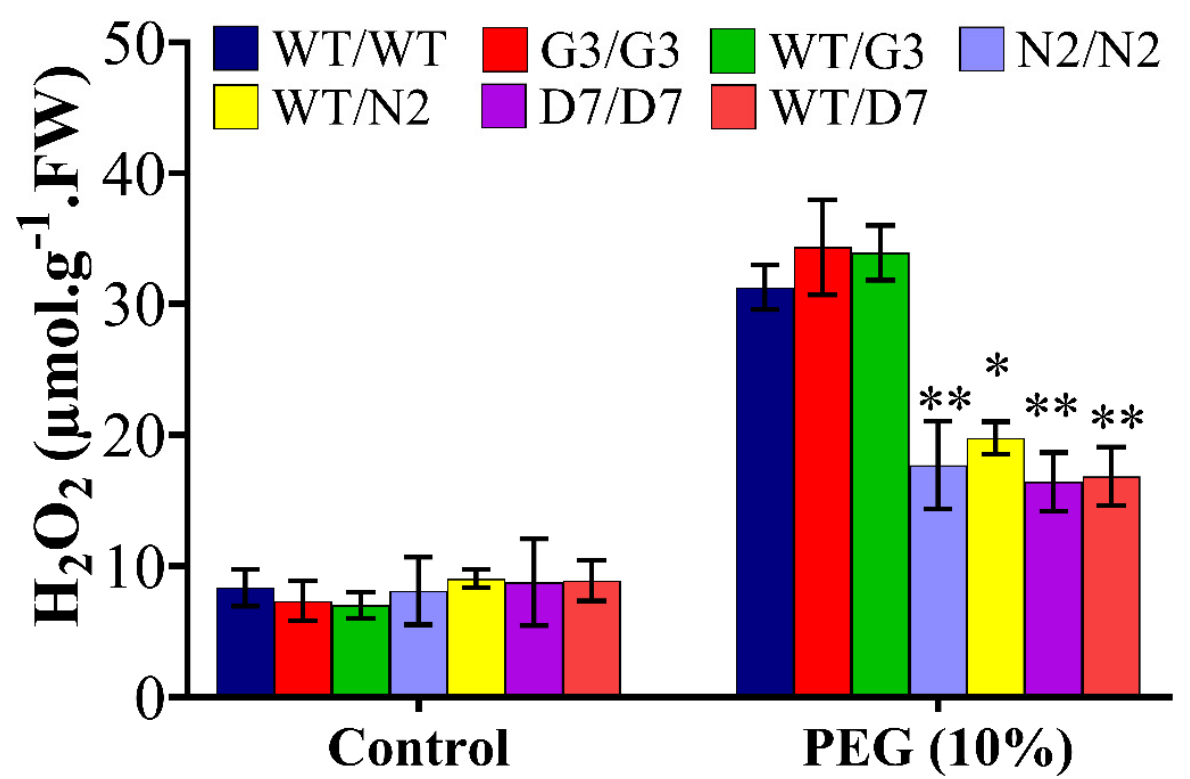

Figure 9. Celluar $\mathrm{H}_{2} \mathrm{O}_{2}$ content in the leaves of WT and transgrafted plants under osmotic stress conditions. Histochemical localization (a) and quantification of hydrogen peroxide content (b) in leaves of transgrafted tobacco plants; WT/WT, G3/G3, WT/G3, N2/N2, WT/N2, D7/D7 and WT/D7 are grafting combinations. The bars represent mean values \pm SEM of three biological replicates (four plants each). Asterisk(s) indicate(s) significant differences between the means of wild type (WT/WT) and transgrafts of each treatment group at ${ }^{*} p<0.05,{ }^{* *} p<0.01$ according to Dunnett test. 


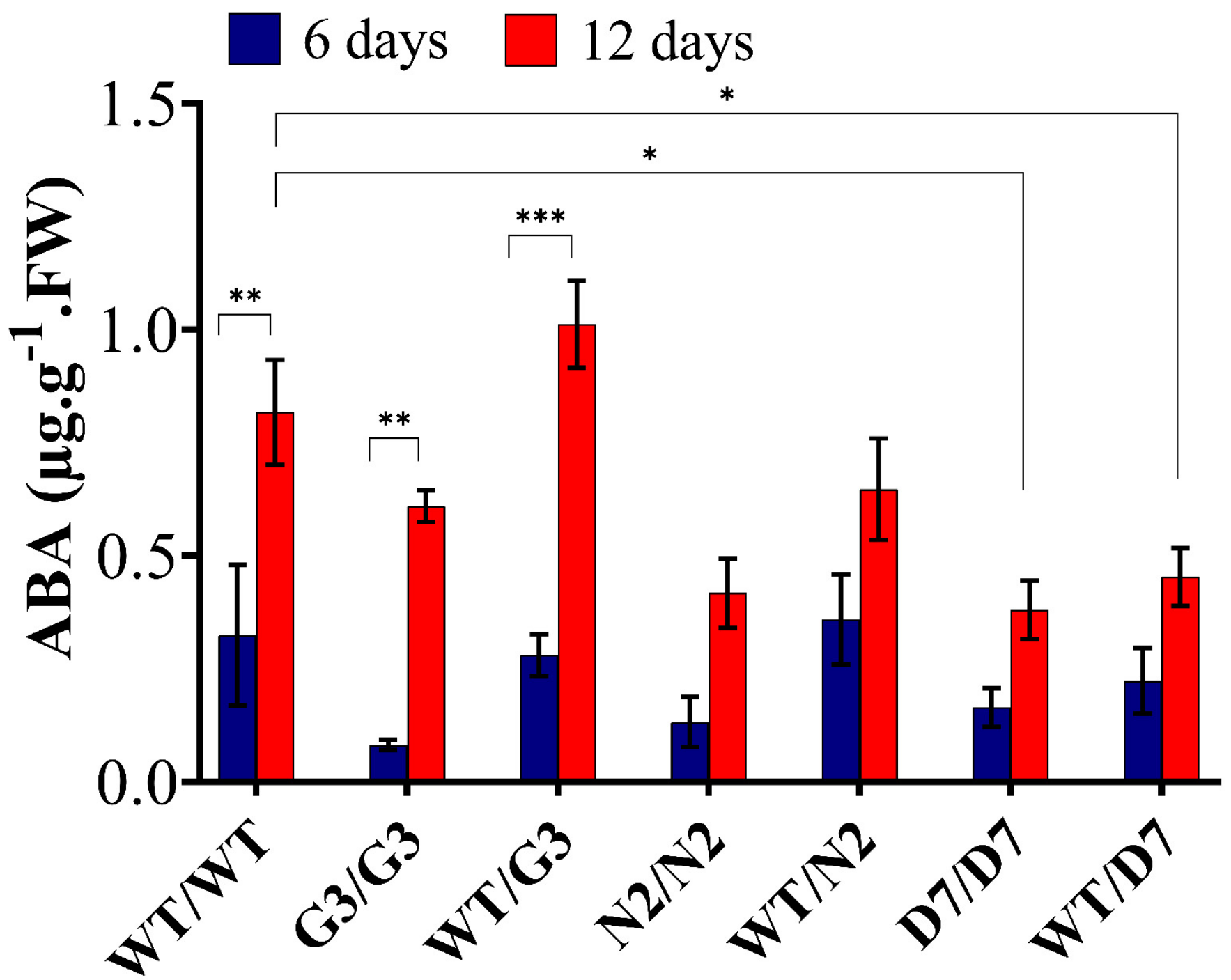

Figure 10. ABA quantification in the leaves of transgrafted tobacco plants under osmotic stress conditions. Abscisic acid (ABA) content was determined in the scion leaves 6 and 12 days of exposure to osmotic stress (10\% PEG). WT/WT, G3/G3, WT/G3, N2/N2, WT/N2, D7/D7 and WT/D7 are grafting combinations. The bars represent mean values \pm SEM of three biological replicates (four plants each). Asterisk(s) indicate(s) significant differences between the means of wild type (WT/WT) and transgrafts of each treatment group at ${ }^{*} p<0.05,{ }^{* *} p<0.01,{ }^{* * *} p<0.001$ according to Dunnett test.

\subsection{Evaluation of Osmotic-Responsive Gene Expression in Transgrafted Tobacco Plants Grown} under Osmotic Stress

The gene expression of three reactive oxygen species (ROS) detoxification genes $(N t C A T, N t S O D$ and $N t A P X)$ and six osmotic response genes (NtERF, NtRD29, NtERD1, $N t M Y C, N t H S P 70$ and NtHSP26) was studied in transgenic and wild-type tobacco plants after three days of PEG-induced stress. In general, the gene expression of all the tested genes was statistically similar among all tobacco gentotypes under control (no-stress) conditions. In addition, G3/G3 and WT/G3 and WT/WT plants showed similar expression levels under stress conditions in all tested genes (Figure 11). Transcript analysis revealed that expression of NtCAT, NtSOD and NtAPX genes increased significantly in transgrafted tobacco plants relative to WT/WT plants exposed to 10\% PEG (Figure 11a-c). Expression of NtERF was also up-regulated by 1.9-, 1.8-, 2.4- and 2.2-folds in transgrafts N2/N2, WT/N2, D7/D7 and WT/D7, respectively, compared to WT/WT in response to OS (Figure 11d). Similarly, NtRD29 showed 2-, 1.9-, 4.6- and 2.7-folds higher in N2/N2, WT/N2, D7/D7 and WT/D7, respectively, than WT/WT under stress conditions (Figure 11e). The expression of $N t E R D 1$ followed the same response as NtRD29 under OS with the highest induction of 6- 
and 4.6-folds in D7/D7 and WT/D7, respectively (Figure 11f). The expression of NtMYC, NtHSP70 and NtHSP26 also exhibited higher transcript levels in transgrafts than WT/WT under stress conditions (Figure $11 \mathrm{~g}-\mathrm{i}$ ). Overall, the expression of the tested ORGs in the scion of N2/N2, WT/N2, D7/D7 and WT/D7 was significantly up-regulated compared to WT/WT after the PEG treatment, suggesting that transgenic rootstocks elevated ORGs expression in WT scion, improving its OS tolerance.

a

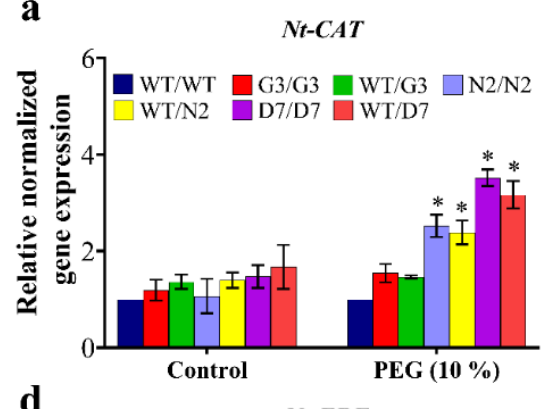

d
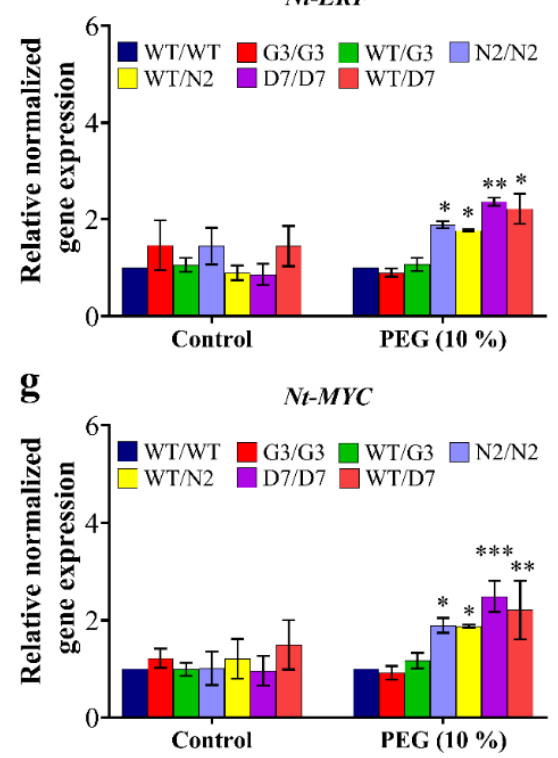

b

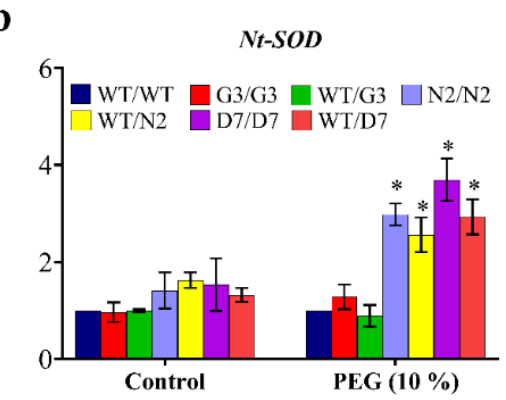

e

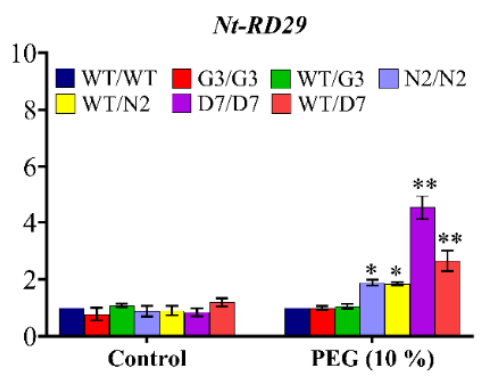

h

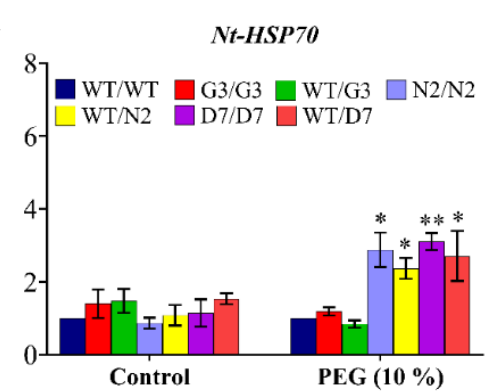

c

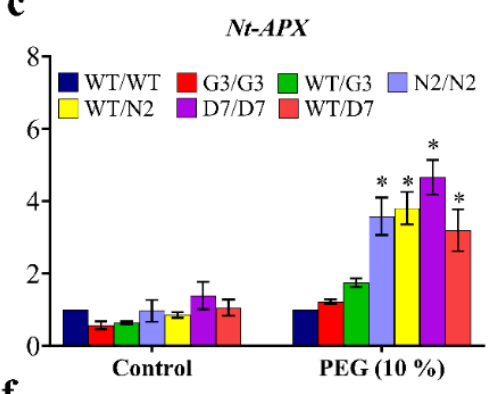

f

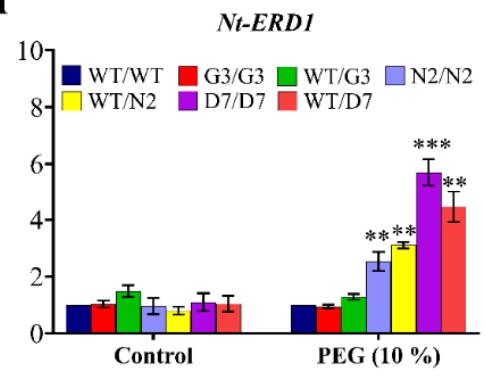

i

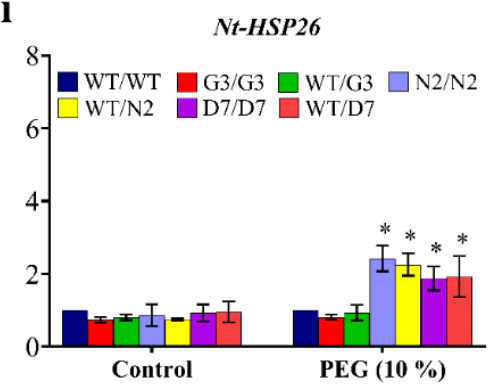

Figure 11. Gene expression analysis in transgrafted tobacco plants under osmotic stress conditions. Normalized relative gene expression of (a) NtCAT, (b) NTSOD, (c) NtAPX, (d) NtERF, (e) NtRD29, (f) NtERD1, (g) NtMYC, (h) NtHSP70, and (i) NtHSP26 genes three days after stress treatment. Genes differentially expressed in plants under stress conditions were normalized with NtEF1. WT/WT, G3/G3, WT/G3, N2/N2, WT/N2, D7/D7 and WT/D7 are grafting combinations. The bars represent mean values \pm SEM of three biological replicates (four plants each). Asterisk(s) indicate(s) significant differences between the means of WT/WT and transgrafts of each treatment group at ${ }^{*} p<0.05,{ }^{* *} p<0.01,{ }^{* * *} p<0.001$ according to Dunnett test.

\section{Discussion}

\subsection{Osmotic Stress Altered Expression Levels of Various ORG Genes}

In this study, 21 ORGs were used to characterize the differences in their gene expression levels under conditions of OS using quantitative real-time RT-PCR (Figure 1). The tested genes are known to be involved in the abscisic acid (ABA) (i.e., DREB, RD29, ERD7, $A B I 2$ and $S N R K$ ), salicylic acid (SA) (i.e., NPR1) and jasmonic acid (JA) signaling pathways (i.e., $M Y C 2, M Y B 2$, and $M Y B 72$ ). In addition, the genes that induce different physiological responses under OS (i.e., ADH1, STZ, UGT, ATPase, LIP2, and AFP4) and six members of the heat shock protein (HSP) family (i.e., HSP21, HSP26, 5P, HSP17, HSP17-6C, HSP17-6A, and HSP18-1) that have previously shown up-regulation under various stress conditions [52-57] were also tested. Numerous previous studies have shown that plants undergo changes in 
the level of expression of many stress-related genes depending on the nature and severity of stress conditions [58,59]. Changes in gene expression that occur following exposure to OS cause a series of physiological and biochemical alterations that contribute to increased OS tolerance. Here, we reported up-regulation in the transcription factors $D R E B, R D 29$, and ERD7 under OS conditions. These genes are believed to be essential members inducing the transcription of other stress-inducible genes [60]. Previous studies also reported that $D R E B$ increases plant tolerance to freezing, drought, and high-salinity stresses when overexpressed in model plant species [61-64]. RD29 has also been found to confer tolerance to different abiotic stresses when overexpressed in Arabidopsis [61] and tobacco [65]. Whereas ERD7 plays an important role in both ABA-dependent and ABA-independent signaling transduction pathways in response to abiotic stresses [66-69].

ORGs that have also been previously shown to play a key role in abiotic stress-related hormone signaling include NPR1 and MYB. Our data showed that NPR1 was significantly up-regulated after $6 \mathrm{~h}$ and $24 \mathrm{~h}$ of OS in the potato scion. It has been demonstrated that StNPR1 gene expression increased after drought stress, suggesting an important role of StNPR1 in plant's response to drought stress [70]. The induction in NPR1 levels can improve plant tolerance to OS through the positive regulation of salicylic acid (SA) as NPR1 is the SA receptor in the plant [71]. MYB transcription factors are also involved in plant responses to abiotic stress via the regulation of the phenylpropanoid pathway, which produces various secondary metabolic compounds involved in abiotic stress response [72] in addition to the regulation of various developmental processes in the stressed plant such as stomatal movement, the control of suberin and cuticular waxes synthesis, and crosstalk between different plant hormones [26]. Another gene family that is known to be involved in stress tolerance is the HSP family. These proteins can scavenge accumulated damaged proteins to maintain cellular homeostasis [73,74]. It has also been shown that HSP improve plant tolerance against abiotic stress by improving physiological processes such as membrane stability, photosynthesis, assimilate distribution, and the efficiency of water and nutrient use [52]. In the current study, the levels of five HSP family members significantly increased in potato in response to OS.

Another stress mitigation strategy that plants follow is to maintain a suitable energy balance during stress conditions via reducing growth by repressing the expression of several genes involved in photosynthesis and carbohydrate metabolism [51,75]. STZ has been demonstrated to be responsive to drought, salt, cold, and abscisic acid by reducing growth, saving plant resources for stress tolerance [75]. The increase in UGT and ADH1 levels after PEG treatment may improve plant adaptation to OS through the biosynthesis and regulation of natural plant products and plant hormones [76] and the accumulation of osmolytes and callose [77], which in turn maintains cell homeostasis [78-80].

\subsection{The Transport of NPR1 Transcripts through Graft-Union}

The movement of mRNA over long distances has been confirmed in several plant species using the heterografting system $[4,13,81-85]$. In the present study, we confirmed the transport of the osmotic responsive gene StNPR1 transcripts from rootstock to scion tissues under both normal and OS conditions (Supplementary Figure S2, Figure 2a,b). We also showed that the gene expression levels of potato NPR1 in the tomato scion increased after exposure to stress compared to the heterograft control (Figure 2a), indicating that OS may be a key factor in regulating the transport of StNPR1 transcripts over long distances. Furthermore, we showed that gene homologs of the same family not necessarily share the same mRNA transport potential. Indeed, among the four members of the potato NPR1-related genes (NIM1-1, NPR6A, NPR6B, and NPR1), only the NPR1 transcripts were detected in the scion of the heterograft.

The results shown in Figure 2a,b demonstrated that StNPR1 has mobile mRNA. However, such mobility was not observed under a transgrafted system, in which WT tobacco scion was grafted to transgenic tobacco rootstocks overexpressing StNPR1. The mRNA mobility over long-distance is not well understood and is likely to be influenced 
by many factors. For instance, the lack of mRNA binding proteins may affect mRNA mobility. mRNA binding proteins have an essential role in mRNA movement and protect mRNA from degradation during the movement over long distances $[15,16,86]$. It has been suggested that the untranslated region (UTR) regions have conserved motifs that conjugate with mRNA binding protein to facilitate their movement $[87,88]$. In the present study, we used the coding region only of StNPR1 for genetic transformation which could explain, at least partially, the lack of transcript mobility from the transgenic rootstock to non-transgenic scion. Further experiments need to be conducted to investigate the role of $5^{\prime}$ and $3^{\prime}$ UTRs of NPR1 in the mobility and translation of its transcripts.

\subsection{Overexpression of StNPR1 and StDREB1 Improved Tobacco Tolerance to Osmotic Stress}

Although several osmotic-responsive genes were evaluated in the current study, our research focused on the characterization of StNPR1 and StDREB that are involved in SA and ABA signaling pathways, respectively. NPR1 is a key regulator involved in plant response to biotic stress, and its regulatory mechanism has been relatively clear. The overexpression of NPR1 in Arabidopsis results in various degrees of resistance to different biotic stresses [89]. Numerous studies have revealed that NPR1 is a key regulator of systemic acquired resistance (SAR), as NPR1 works as a regulatory component that functions downstream of SA in the signal transduction cascade that mediates SAR induction [90]. Moreover, NPR1 is a master regulator of the salicylic acid (SA) signaling pathway as it works as a receptor for SA [71,91,92]. However, information about the role and the function of NPR1 in plant response to abiotic stress is largely unknown. DREB, on the other hand, is well known for its role in increasing tolerance to freezing, drought, and high salinity when overexpressed in model plant species [61-64,93]. In fact, DREB is a transcription factor that binds to the dehydration-responsive element (DRE)/C repeat (CRT), a cis-acting element that is involved in the up-regulation of several osmotic stress-related genes [60].

To explore the potential role of StNPR1 and StDREB1 in enhancing plant tolerance to OS, we overexpressed the coding region of StNPR1 and StDREB1 in tobacco using the constitutive CaMV35S promoter (Figure 4). The potential tolerance of the transgenic plants was initially assessed through leaf disc senescence assay (Figure 5) under $\mathrm{NaCl}(100 \mathrm{mM})$, mannitol $(200 \mathrm{mM})$ and PEG $(10 \%)$ stress conditions. The increase in EL and chlorophyll degradation, besides reducing cell viability has been confirmed to be a major markers of stress [94-96]. Under salt and OS, transgenic lines showed lower electrolyte leakage, more cell viability, and delayed chlorophyll degradation compared to control plants (WT and G3). This indicated that transgenic lines had better membrane permeability, lower oxidative stress and healthier leaf discs with higher photosynthetic capacity than the control group. These results are consistent with those reported in transgenic tobacco overexpressing apple MdDREB76 [93]. Additionally, SINPR1 knock-out tomato plants have illustrated higher sensitivity to drought stress with higher $\mathrm{H}_{2} \mathrm{O}_{2}, \mathrm{MDA}$ and electrolytic leakage, suggesting that NPR1 is essential for alleviating oxidative stress and cell membrane damage [70]. NPR1 has also been reported to induce oxidative stress tolerance in Arabidopsis exposed to salt stress through NPR1-dependent SA signaling which was related to the control of $\mathrm{Na}^{+}$ flux in the roots and consequently its long-distance transport into the shoot under stress conditions [97].

$\mathrm{N} 2$ and D7 transgenic lines showed higher GUS gene expression which should also reflect the expression of the corresponding chimeric genes of StNPR1 and StDREB1, respectively. Therefore, N2 and D7 were selected to examine the effect of different stress conditions on the morphology of the transgenic plants. The morphological changes were monitored under $100 \mathrm{mM} \mathrm{NaCl}, 200 \mathrm{mM}$ mannitol and 10\% PEG. N2, D7. Unsurprisingly, G3 plants expressing GUS only showed similar morphology to WT (Figure 6a). However, transgenic lines N2 and D7 had increased shoot length, fresh weight (FW), dry weight (DW) and root weight under different stress conditions compared to WT and G3. Previously, overexpression of Syntrichia caninervis DREB8, potato DREB1 and tomato DREB3 in Arabidopsis, potato and tobacco, respectively, increased root length and fresh weight and 
dry weight of transgenic seedlings growing under salt stress [95,98,99]. NPR1 also plays an important role in controlling plant biomass under abiotic stress. Indeed, Arabidopsis npr1 mutant, which lacks NPR1-dependent SA signaling, and plants overexpressing NPR1, have been tested under salt stress. The results showed higher fresh weight in plants overexpressing NPR1 and lower fresh weight in npr1 mutant growing under salt stress compared to wild-type Arabidopsis [97]. Our data also showed that overexpression of StDREB1 significantly increased root weight in D7 seedling relative to WT and G3 under normal and OS conditions. Such change in root architecture could be attributed to ABA content that works as a negative regulator of lateral root formation under abiotic stress [26]. Interestingly, ABA levels in D7 plants were significantly lower than WT, under stress conditions.

\subsection{The N2 and D7 Transgenic Rootstocks Improved the Growth Parameters of WT-Scions under Osmotic Stress}

The effect of the tolerant transgenic rootstocks N2 and D7 on the WT-scions was examined under OS induced by PEG (10\%) for 12 days. Relative water content and cell viability were significantly higher in transgrafted plants (N2/N2, WT/N2, D7/D7 and WT/D7), which alleviated stress injury, and thus, stress-induced damage was reduced compared to the control group (WT/WT, G3/G3 and WT/G3), whereas EL, which is a common stress marker, was significantly lower in scions of transgrafted plants compared to the scions of the control group indicating better membrane integrity [100]. Plants produce ROS under normal conditions during photosynthesis through electron transport chain in photosystem II (PSII) [101]. ROS also over-accumulate under abiotic stress, leading to oxidative stress conditions which in turn inhibits the PSII repair system [100,101]. High accumulation of ROS in the chloroplasts under stress conditions was proven to promote chlorophyll degradation, besides its negative effect on membrane permeability $[100,102]$. Here, it was observed that transgrafts with N2 and D7 rootstocks showed significantly higher chlorophyll content and reduced EL under OS compared to the control group. Control grafts (WT/WT, G3/G3 and WT/G3) also showed intense brown color precipitation after DAB staining indicating a higher level of $\mathrm{H}_{2} \mathrm{O}_{2}$ compared to transgrafted plants (N2/N2, WT/N2, D7/D7 and WT/D7) under OS. These observations indicate that StNPR1 and StDREB1 may be involved in alleviating oxidative stress. Indeed, our gene expression analyses showed significant up-regulation of tobacco genes encoding antioxidant enzymes such as superoxide dismutase (SOD), ascorbate peroxidase (APX) and catalase (CAT) in scion tissues grafted to transgenic N2 and D7 rootstocks, which could explain how these transgenes could contribute towards ROS homeostasis under OS [100]. Overall, our results demonstrate StNPR1 and StDREB1 transgenic rootstocks can modulate the physiological properties of the scion, increasing its tolerance to OS.

\subsection{ABA Level in the Scion Is Rootstock Dependent}

ABA is an essential stress-related hormone that is produced in plants to reduce the adverse effects of abiotic stress [34,101]. ABA is mainly produced in the root system and acts as a long-distance signal from the roots to the shoots to reduce stomatal conductance and consequently reduces transpirational water loss [3,34,36]. Li et al. (2018) [39] also reported that, under salt stress, the accumulation of ABA in tomato roots is partially regulated by shoot $\mathrm{ABA}$ export. The current study investigated the effect of tolerant transgenic rootstocks on ABA content in WT-scions under OS. ABA level was undetectable in all grafting combinations at zero time point when there was no stress. However, after 6 and 12 days of exposure to PEG, a marked increase in ABA content was observed in response to OS. Interestingly, the control plants showed around a 2-times increase in ABA content compared to N2/N2, WT/N2 at 12 days, but such an increase was not statistically significant. Additionally, ABA level was significantly lower in D7/D7 and WT/D7 than the control group at 12 days, suggesting that transgenic rootstocks overexpressing StDREB1 negatively regulated the level of ABA in the leaves of WT-scion. Previous studies showed that the level of ABA in the rootstock regulated ABA content in the scion $[34,39,41]$, which in turn is associated with gas exchange, stomatal conductance and water status [103]. The 
lower ABA content in D7/D7 and WT/D7 indicated that StDREB1 might improve OS tolerance in tobacco through an ABA-independent signaling pathway. Along the same vein, overexpressing OsDREB6 and LIDREB1G was found to enhance tolerance to abiotic stress in ABA-independent signaling pathway under different abiotic stresses $[104,105]$. We also found that the leaf content of ABA in the control grafts significantly increased from 6 to 12 days in WT/WT, G3/G3 and WT/G3; which in turn may have reduced stomatal conductance, gas exchange, consequently reducing photosynthetic rate $[39,99]$. On the other hand, the notable increase in ABA content from 6 to 12 days in N2/N2, WT/N2, D7/D7 and WT/D7 was insignificant and still lower than the control plants. This suggested that at six days, the plants might have acquired OS tolerance to maintain physiological processes using a different strategy to maintain water status, such as improved root system and/or higher osmolytes content, than the continuous increase in ABA and enhanced stomatal closure to reduce water loss, thereby lowering the photosynthesis which may promote the onset of senescence [99]. It has also been found that the increase in rootstock vigor is correlated with the reduction in ABA concentrations. Indeed, rootstocks with higher ABA levels showed early senescing and decreased net photosynthesis [41]. Overall, $\mathrm{ABA}$ is one of the most important long-distance signals in controlling plant growth under abiotic stress by regulating photosynthesis and transpiration, although the involvement of other factors cannot be ruled out and remains to be investigated.

\subsection{Transgenic Rootstocks Improve WT-Scion via Up-Regulation of Various ORGs}

This study investigated the influence of the transgenic rootstocks on gene expression regulation in the WT-scion. As mentioned above, the transcripts of tobacco NtSOD, NtCAT and NtAPX genes were increased by OS in WT-scions grafted on N2 and D7 compared to control plants. The increased gene expression of $C A T, S O D$ and $A P X$ was reported in previous transgenic studies where MdDREB76 [93] and SbUSP [96] overexpressed in tobacco enhanced plant tolerance to salt, drought and OS. The gene expression levels of tobacco $N t E R F, N t R D 29$ and $N t E R D 1$ were also found to be up-regulated in the scion of transgrafted plants relative to the control plants. Indeed, the transcript levels of these genes were almost 2-3 folds higher in D7/D7 and WT/D7 compared to N2/N2 and WT/N2. This increase might result from $R D 29 A, E R D 1$ and $E R F$ being major abiotic stress-related genes that act downstream $D R E B$ signaling [62]. Previous studies reported that overexpressing of MdDREB76 and ScDREB8 in tobacco and Arabidopsis, respectively, elevated the gene expression of $E R F, E R D 1, E R D 10 A E R D 10 D$, conferring salt and drought tolerance to the transgenic plants $[93,98]$. The expression of $M Y C 2$ was also highly regulated in WT-scions grafted on N2 and D7 compared to control group under OS (Figure 11g). It has been found that MYB transcription factor plays a key role in ABA signaling pathway [81] through the induction of stress-related genes such as RD22. MYB has also been reported to be involved in stomatal conductance under stress conditions, which in turn controls water status in plants $[26,106]$. The tomato Slnpr 1 loss of function mutant has shown a lower drought tolerance that was associated with the downregulation of various drought-related genes, including DREB, suggesting that NPR1 might be involved in ABA signaling pathway under drought stress [70]. This might explain the up-regulation of $N t E R F, N t R D 29$, $N t E R D 1$ and MYC genes in the scion of $\mathrm{N} 2 / \mathrm{N} 2$ and WT/N2 compared to the control plants. Heat shock proteins (HSP) are a large group of transcription factors that regulate protein transport, folding and maintenance of correct protein structure to protect cells from abiotic stress [107]. In the current study, the up-regulation of NtHSP70 and NtHSP26 was observed in transgrafted plants relative to the control plants (Figure 11h,i). Likewise, the overexpression of MdDREB76, LIDREB1G and ScDREB8 elevated the transcript level of NtHSP70 and NtHSP26 in tobacco and Arabidopsis plants growing under different abiotic stress conditions imparting stress tolerance to the transgenic plants $[93,98,105]$. Additionally, SA is involved in the induction of various genes encoding heat shock proteins (HSPs) and chaperones [108]. In fact, Arabidopsis NPR1 transcripts are up-regulated in response to low temperatures and NPR1 protein interacts with heat shock transcription factor 1 
(HSFA1) to induce the expression of HSFA1-related genes under cold stress including HSP70 in Arabidopsis [109]. Overall, the results of the current study indicated that transgenic rootstocks overexpressing StNPR1 and StDEB1 confer OS tolerance to the WT-scion through up-regulation of genes encoding transcription factors and major enzymes that alleviate oxidative stress and modulate physiological processes, resulting in a better plant performance under stress conditions compared to WT/WT plants.

\section{Conclusions}

The identification of several ORGs that are highly up-regulated in potato following OS indicates that various signaling molecules are involved in improving OS tolerance in potato plants. Although we found that StNPR1 transcripts were transported from the potato rootstock to tomato scion, mRNA of StNPR1 was not transported from the transgenic rootstock to the wild-type scion in transgrafted tobacco. Our results also revealed that tolerant rootstocks overexpressing StNPR1 and StDREB1 enhanced the growth and performance of wild-type scions in transgrafted tobacco by activating various osmotic responsive genes. These genes encode for enzymes and transcription factors and that alleviate oxidative stress and modulate physiological properties of the scion, including RWC, EL, CV, chlorophyll and $\mathrm{H}_{2} \mathrm{O}_{2}$ contents, thereby improving OS tolerance in transgrafted tobacco plants. Together, the results of the present study elucidated, at least partially, the underlying mechanisms of the induced defense response in WT-scions grafted to transgenic rootstocks in osmotically stressed transgrafted tobacco. Our study also paves the way for incorporating StNPR1 and StDREB1 as two potential candidates for producing stressresilient crops through the transgrafting technology, which could have major implications in the horticulture industry.

\section{Materials and Methods}

\subsection{Grafting, Transgrafting and Growth Conditions}

Four-week-old tomato seedlings and eight-week-old potato seedlings with uniform stem diameter (around $5 \mathrm{~mm}$ ) were used as the scion and rootstock, respectively, to produce a heterograft using cleft grafting method modified from Notaguchi et al. (2012) [8]. In brief, a clear sharp wedge was made by a sharp blade at the bottom of the scion, and then it was inserted into a V-shaped slit made at the top of the rootstock $(10-15 \mathrm{~cm})$. All the grafted plants were grown in the mist bed for five days. The tomato and potato grafted plants were transferred to a greenhouse which had light intensity of $300 \mu \mathrm{mol} \mathrm{m}{ }^{-2} \mathrm{~s}^{-1}$, a day and a night-time temperature of $21 \pm 2{ }^{\circ} \mathrm{C}$ and a diurnal cycle of $16 \mathrm{~h}$ light $/ 8 \mathrm{~h}$ dark. The $\mathrm{F}_{2}$ seeds of G3, N2 and D7 were germinated on MS [110] selection medium with vitamins (Phyto Technology laboratories, Shawnee Mission, KS, USA) and containing $20 \mu \mathrm{g} / \mathrm{mL}$ hygromycin (Goldbio, St. Louis, MO, USA) and $300 \mu \mathrm{g} / \mathrm{mL}$ timentin (PhytoTechnology Laboratories, Shawnee Mission, KS, USA) for two weeks while WT seeds were germinated on the same medium without the antibiotics. The seedlings which survived were subcultured on the selection medium for 5 weeks before transferring the plants into the growth chamber. Transgrafting was performed using 5 weeks old tobacco plants following the same procedure as described above to create six transgrafting treatments and wild-type homograft. All grafted tobacco plants were grown in a growth chamber with light intensity of $200 \mu \mathrm{mol} \mathrm{m}{ }^{-2} \mathrm{~s}^{-1}$, a constant temperature of $23 \pm 2{ }^{\circ} \mathrm{C}$ and $16 \mathrm{~h} \mathrm{light}$.

\subsection{Plant Materials and Sample Collection for Analysis of mRNA Transport}

Tomato seeds (Solanum lycopersicum 'Beefsteak') were germinated and grown in a propagation mix in a greenhouse. Four-week-old potato rooted microshoots (Solanum tuberosum 'Gold Rush') were transferred from an in vitro culture to a mist bed for five days and then were moved to the same growth conditions as the tomato seedlings. Experiments were performed using the tomato/potato heterograft $(\mathrm{T} / \mathrm{P})$, potato/potato homograft $(\mathrm{P} / \mathrm{P})$ as the positive control and tomato/tomato homograft $(\mathrm{T} / \mathrm{T})$ as the negative control. Volume of $200 \mathrm{~mL} /$ plant of 30\% polyethylene glycol (PEG 6000) (Sigma-Aldrich, St. Louis, MO, USA) 
was used to induce OS; the same amount of water was added to the control. The sampling of the scion was performed $6 \mathrm{~h}$ after inducing stress by taking $5 \mathrm{~cm}$ of the scion's stem ( $1 \mathrm{~cm}$ above the graft union). All the samples were flash-frozen in liquid nitrogen before storing them at $-80{ }^{\circ} \mathrm{C}$ for further use. Three reference genes (GTP-binding protein SAR1A (GTP), TIP41-like family protein (TIP), and Clathrin adaptor complexes (Clathrin)), which have shown highly stable expression levels in tomato [111], were used in the present study. To make sure that the normalized relative gene expression of the potato genes with mobile transcripts in tomato scion of the heterograft is normalized based on tomato transcripts only and not other mobile transcripts from potato rootstock, the movement of the housekeeping genes was determined using specific potato primers (StGTP, StTIP, and StClathrin), which are presented in Supplementary Table S1.

\subsection{Tobacco Transformation and Molecular Confirmation of Transgenics}

The constructs of pCambia1301:StNPR1 and pCambia1301:StDREB1 were synthesized by Biomatik, USA (http://www.biomatik.com), accessed on 15 May 2018. Constructs containing a hygromycin resistance selectable marker, regulated by CaMV35S enhanced promoter and the transformed genes downstream of another CaMV 35S promoter, were introduced into tobacco (Nicotiana tabacum) plants through Agrobacterium tumefaciens (EHA105)-mediated leaf disc method $[112,113]$. The regenerated transformants $\left(\mathrm{F}_{1}\right)$ were screened by growing on a Murashige and Skoog MS + vitamins selection medium supplemented with $30 \mu \mathrm{g} / \mathrm{mL}$ hygromycin and $300 \mu \mathrm{g} / \mathrm{mL}$ Timentin, 3\% sucrose, and $0.70 \%$ $(w / v)$ agar (Fisher Chemical, Fair Lawn, NJ Belgium). The $\mathrm{pH}$ was adjusted to 5.7. The transgene's presence was confirmed by PCR amplification using genomic DNA as a template in the wild type (WT), G3 (the transgenic line overexpressing the empty vector with GUS), N2 and N4 (the transgenic lines over-expressing StNPR1) and D1, D7, and D11 (the transgenic lines over-expressing StDREB1). NtActin was used as a reference gene. The relative gene expression of GUS was analyzed in transgenic lines by qRT-PCR with three biological and three technical replicates. Elongation factor-1 $\alpha$ (NtEF1) gene was used as the internal control.

\subsection{Analyses of $F_{1}$ and $F_{2}$ Transgenic Plants Exposed to Abiotic Stresses}

The stress tolerance capacity of the transgenic lines was initially tested using leaf disc assay. Leaf disc assay was performed using leaves of six weeks old $\mathrm{F}_{1}$ plants modified from Singla-Pareek et al. (2003) [114]. The $2 \mathrm{~cm}$ diameter leaf discs of transgenic lines (G3, N2, N4, D1, D7 and D11) and WT were punched out and floated on water supplemented with $100 \mathrm{mM}$ sodium chloride ( $\mathrm{NaCl}$ ) (Fisher Scientific, Fair Lawn, NJ, USA), $200 \mathrm{mM}$ mannitol (Phyto Technology laboratories, Shawnee Mission, KS, USA) and 10\% PEG for 9 days. The experiment was maintained on the bench at room temperature, and phenotypic changes were monitored over 9 days. The effect of stress treatments was evaluated by visually analyzing phenotypic changes among leaf discs along with determination of physiological parameters including electrolyte leakage (EL), cell viability (CV), and chlorophyll content.

The $F_{2}$ seeds of G3, N2 and D7 were germinated on MS+vitamins selection medium containing $20 \mu \mathrm{g} / \mathrm{mL}$ hygromycin and $300 \mu \mathrm{g} / \mathrm{mL}$ timentin for two weeks while WT seeds were germinated on MS+vitamins for the same duration. The surviving seedlings were subcultured on MS+Vitamins selection media supplemented with $100 \mathrm{mM} \mathrm{NaCl}$, $200 \mathrm{mM}$ mannitol and 10\% PEG and incubated for four weeks under controlled environment conditions. The transgenic lines were analyzed for shoot length, root length, fresh weight (FW), dry weight (DW) and root fresh weight.

\subsection{Stress Tolerance of Transgrafted Tobacco Plants}

To assess transgraft tolerance to OS, all the grafts were drenched with $10 \%$ PEG solution after one month of grafting. The grafting treatments were: wild type homograft, i.e., wild type scion grafted on wild type rootstock (WT/WT), G3 scion grafted to G3 rootstock (G3/G3), WT scion grafted on G3 rootstock (WT/G3), N2 scion grafted on N2 
rootstock (N2/N2), WT scion grafted on N2 rootstock (WT/N2), D7 scion grafted on D7 rootstock (D7/D7) and WT scion grafted on D7 rootstock (WT/D7). Each treatment contained 12 grafts divided into three biological replicates. Leaf samples were collected at zero-day (control), 3, 6, 9 and 12 days after treatment for physiological, biochemical and molecular analyses.

\subsection{Measurement of Electrolyte Leakage, Cell Viability, Relative Water Content and Chlorophyll Content}

The injuries in the cell membrane were assessed by estimating the electrolyte leakage using an electrical conductivity meter, as per Bajji et al. (2002) and Sharma et al. $(2019)[93,115]$. Fresh leaves were cut into $0.5 \mathrm{~cm}$ discs, six-leaf discs were washed with deionized water, then immersed in $20 \mathrm{~mL}$ of deionized water and kept on the shaker at $100 \mathrm{rpm}$ at room temperature. Initial electrical conductivity (IEC) was recorded after 24 (h). The samples were then autoclaved at $121{ }^{\circ} \mathrm{C}$ for $20 \mathrm{~min}$ to release all the electrolytes. After cooling down the samples to room temperature, the final electrical conductivity (FEC) was measured. Electrolyte leakage was calculated by the formula: EL $(\%)=($ IEC $/ F E C) \times 100$. Cell viability was estimated by 2,3,5-triphenyltetrazolium chloride (TTC) (Sigma-Aldrich, St. Louis, MO, USA) assay [116]. Four $0.5 \mathrm{~cm}$ leaf discs were incubated in $0.1 \%$ TTC at $37^{\circ} \mathrm{C}$ in the dark for $6 \mathrm{~h}$. Samples were then incubated in $1 \mathrm{~mL}$ of $95 \%$ ethanol (Greenfield Global, Brampton, ON, Canada) at $60^{\circ} \mathrm{C}$ for $5 \mathrm{~min}$. The absorbance of formazan was recorded at $470 \mathrm{~nm}$ using a plate reader (Biotech, USA). Cell viability was determined using the formula: $\mathrm{CV}(\%)=\left(1-\left(\mathrm{OD}_{0}\right.\right.$ $\left.\left.-\mathrm{OD}_{\mathrm{T}} / \mathrm{OD}_{0}\right)\right)^{*} 100$, where $\mathrm{OD}_{0}$ is the $\mathrm{OD}$ of the sample at zero time and $\mathrm{OD}_{\mathrm{T}}$ is the $\mathrm{OD}$ of the same treatment after stress treatment. The relative water content (RWC) was recorded as described by Aneja et al. (2015) [55], with minor modifications. The fresh weight (FW) of leaf segments was immediately measured. Then, the leaves were soaked in distilled water at room temperature for $24 \mathrm{~h}$, the turgid weight (TW) was recorded. The leaves were dried in the oven for $24 \mathrm{~h}$ at $70^{\circ} \mathrm{C}$, and the dry weight (DW) was recorded. The RWC was calculated using the formula: $\mathrm{RWC}(\%)=(\mathrm{FW}-\mathrm{DW}) /(\mathrm{TW}-\mathrm{DW}) \times 100$. Total chlorophyll was determined through immersing $50 \mathrm{mg}$ from the fresh leaves in ethanol $95 \%$ and incubation at $70{ }^{\circ} \mathrm{C}$ for $5 \mathrm{~min}$. Then, the absorbance was measured at room temperature using a plate reader (Biotech, USA). Total chlorophyll amount was determined as described by Lichtenthaler (1987) [117].

\subsection{In Situ Localization and Estimation of Hydrogen Peroxide $\left(\mathrm{H}_{2} \mathrm{O}_{2}\right)$}

The accumulation of $\mathrm{H}_{2} \mathrm{O}_{2}$ was detected through the histochemical staining of the leaves with 3,3-diaminobenzidine (DAB) (Sigma-Aldrich St. Louis, MO, USA) method, modified from Daudi and O'Brien (2012) [118]. Leaves were immersed in DAB solution in the dark on the shaker at $100 \mathrm{rpm}$ for $5 \mathrm{~h}$. The chlorophyll was bleached by incubating the leaves with ethanol at $90{ }^{\circ} \mathrm{C}$ for $5 \mathrm{~min}$. The $\mathrm{H}_{2} \mathrm{O}_{2}$ concentration was determined as described earlier by Patterson et al. (1984) [119]. Then, $50 \mathrm{mg}$ of ground leaves of the scions were extracted in $500 \mu \mathrm{L}$ of precooled acetone and centrifuged for $10 \mathrm{~min}$ at $1500 \times g$. Titanium chloride (Sigma-Aldrich St. Louis, MO, USA) ( $2 \%$ v/v of the extracted supernatant) and concentrated ammonia $(100 \mu \mathrm{L})$ were added to the supernatant prior to centrifuging the reaction mixture at $1500 \times g$ for $10 \mathrm{~min}$. Absorbance was read at $410 \mathrm{~nm}$, and the $\mathrm{H}_{2} \mathrm{O}_{2}$ concentration was calculated according to the standard curve for peroxide determination.

\subsection{Extraction and Analysis of $A B A$}

ABA content in tomato and potato was extracted and analyzed using an LC-MS method adopted from Ayyanath et al. (2021) [120]. In brief, leaf samples were ground in liquid nitrogen to a fine powder. Then, $150 \mathrm{mg}$ of each sample was extracted with $500 \mu \mathrm{L}$ extraction solution (50\% $\mathrm{MeOH}$ (Thermo Scientific, Fair Lawn, NJ, USA) and $4 \%$ acetic acid (Fisher Scientific, Mississauga, ON, Canada) in Milli-Q water), and the samples were sonicated on ice for $30 \mathrm{~min}$ prior to centrifugation for $2 \mathrm{~min}$ at 13,000 rpm. Subsequently, the supernatant was dispensed into a fresh tube and diluted $5 \times$ in $10 \mathrm{mM}$ ammonium acetate (Sigma Aldrich, Mississauga, ON, Canada) ( $\mathrm{pH}$ 9; adjusted with ammonium hydroxide (Sigma Aldrich, Mississauga, ON, Canada)). Samples (500 $\mu \mathrm{L}$ each) 
were filtered-centrifuged using $0.22 \mu \mathrm{m}$ Millipore tubes and the supernatant was used for quantification using ultra-performance liquid chromatography (ULPC) as described by Erland et al. (2017) [121]. Aliquotes of $3 \mu \mathrm{L}$ were injected onto a Waters Acquity BEH Column $(2.1 \times 50 \mathrm{~mm}$, i.d. $2.1 \mathrm{~mm}, 1.7 \mu \mathrm{m})$ on a Waters Acquity Classic UPLC system with detection using an Aquity QD single quadrupole mass spectrometer (MS) controlled by Empower 3 (Waters, Mississauga, ON, Canada). Samples were run on a gradient with A-10 mM ammonium acetate $\mathrm{pH}$ 9, adjusted with ammonium hydroxide; $\mathrm{B}-100 \% \mathrm{MeOH}$ with initial conditions of $95 \%$ A $5 \%$ B increased to $5 \%$ A $95 \%$ B over 4.5 min using an Empower curve of 8 . Column temperature was $40{ }^{\circ} \mathrm{C}$ and flow rate was $0.5 \mathrm{~mL} / \mathrm{min}$. Capillary voltage was $0.8 \mathrm{kV}$, and probe temperature was $500{ }^{\circ} \mathrm{C}$ with a gain of five. ABA was monitored in single ion recording mode and quantified in ng. $\mathrm{g}^{-1} \mathrm{FW}$ using the standard curve.

ABA levels in tobacco leaves were also determined using the methods described by Ayyanath et al. (2021) [120] with some modifications. In brief, leaf samples were ground in liquid nitrogen to a fine powder. Then, $150 \mathrm{mg}$ of each sample was extracted with $500 \mu \mathrm{L}$ extraction solution $(10 \mathrm{mM}$ ammonium acetate $\mathrm{pH} 9.0)$ vortexed for $1 \mathrm{~min}$ at maximum speed. Then, $100 \mu \mathrm{L} 5 \%$ acetic acid (glacial, Fisher Scientific, Mississauga, ON, Canada) was added and vortexed for a further $1 \mathrm{~min}$ at the maximum speed. Samples were centrifuged at $14,000 \times \mathrm{g}$, at $4{ }^{\circ} \mathrm{C}$ for $15 \mathrm{~min}$. The supernatant was used for analysis following Erland et al. (2017) [121] with some modifications. Samples (5 $\mu \mathrm{L}$ each) were injected onto a Waters Acquity BEH Column $(\mathrm{C} 18,1.7 \mu \mathrm{m}, 2.1 \times 50 \mathrm{~mm})$ on a Waters Acquity Classic ultra-performance liquid chromatography (UPLC) system with detection using an Aquity QDa single quadrupole mass spectrometer (MS) controlled by Empower 3 (Waters, Canada). Samples were run on a gradient with A- $0.1 \%$ Formic Acid (Thermo Scientific, Fair Lawn, NJ, USA); B-100\% Acetonitrile (Thermo Scientific, Fair Lawn, NJ, USA) with initial conditions of $97 \%$ A and 3\% B increased to 3\% A 97\% B for $4.5 \mathrm{~min}$, then $97 \% \mathrm{~A}$ and $3 \% \mathrm{~B}$ at $4.6 \mathrm{~min}$. Column temperature was $40{ }^{\circ} \mathrm{C}$, autosampler temperature was $4.0^{\circ} \mathrm{C}$ and flow rate was $0.5 \mathrm{~mL} / \mathrm{min}$. ABA was monitored in single ion recording mode and quantified in $\mu \mathrm{g} . \mathrm{g}^{-1} \mathrm{FW}$ using standard curve. Capillary voltage was $0.8 \mathrm{kV}$ and probe temperature was $500{ }^{\circ} \mathrm{C}$ with a gain of five.

\subsection{DNA and RNA Extraction and Expression Analysis of Abiotic Stress-Responsive Genes}

Tissue samples were ground to a fine powder in liquid nitrogen, after which total RNA was extracted using CTAB [122]. cDNA syntheses were carried out from $2000 \mathrm{ng}$ (from tomato and potato) and $2500 \mathrm{ng}$ (from tobacco) of purified RNA in a $20 \mu \mathrm{L}$ reverse transcription reaction mixture using a High-Capacity cDNA Reverse Transcription Kit (Applied Biosystems, Vilnius, Lithuania) following the manufacturer's instructions. The cDNA was diluted $1 / 10$ with ultrapure water. DNA was extracted using a DNA extraction kit (QIAGEN, Hilden, Germany) following the manufacturer's instructions. The expression analysis of the selected osmotic responsive genes was quantified through quantitative realtime PCR (qRT-PCR) with three biological and three technical replicates for each sample along with negative control. The qRT-PCR reaction was performed in a $10 \mu \mathrm{L}$ reaction volume. The mixture contained $2.5 \mu \mathrm{L}$ of cDNA, $1 \mathrm{X}$ SsoFast ${ }^{\mathrm{TM}}$ EvaGreen ${ }^{\circledR}$ Supermix (BioRad, California, CA, USA) and $0.4 \mu \mathrm{M}$ of each primer. The qRT-PCR reactions were carried out using CFX Connect ${ }^{\mathrm{TM}}$ Real-Time System (Bio-Rad, Singapore) for one denaturation cycle at $95{ }^{\circ} \mathrm{C}$ for $30 \mathrm{~s}$ then 40 cycles of $95^{\circ} \mathrm{C}$ for $10 \mathrm{~s}$ (denaturation), followed by $60{ }^{\circ} \mathrm{C}$ for $20 \mathrm{~s}$ (annealing and extension). Normalized relative fold expression was calculated using the $2^{-\Delta \Delta C T}$ method and $2^{-\Delta C T}$ method was used to calculate relative gene expression. Semi-quantitative-reverse transcription (RT-PCR) analysis was performed using Platinum ${ }^{\circledR}$ PCR SuperMix to amplify $613 \mathrm{bp}, 501 \mathrm{bp}$ of Actin and StNPR1, respectively, (Figure 2b) and $432 \mathrm{bp}, 524 \mathrm{bp}, 501 \mathrm{bp}$ and $534 \mathrm{bp}$ of NtActin, GUS, StNPR1 and StDERB1, respectively, in transgenic tobacco plants (Figure $4 \mathrm{~b}$ ) after 36 cycles. The primers used for gene expression analysis are shown in Supplementary Tables S1 and S2. 


\subsection{Statistical Analysis}

All the plants were arranged in a complete randomized design (CRD). An analysis of variance (ANOVA) was performed using GraphPad Prism v9. Least square means of three independent biological replicates were compared using Dunnett or Tukey-Kramer test with $\alpha=0.05$ level. Test of normality was performed prior to any analysis, and the log model was used to transfer the date from non-Gaussian to Gaussian when required. The means \pm standard error of mean responses of each parameter of the three replications were presented in the graphs. The results were confirmed by repeating the experiments twice.

Supplementary Materials: The following are available online at https:/ / www.mdpi.com/article/10 $.3390 /$ ijms22168398/s1, Figure S1: Transport of housekeeping mRNAs from the potato rootstock to the tomato scion $6 \mathrm{~h}$ after exposure to osmotic stress, Figure S2: Transport of ORG mRNAs from the potato rootstock to the tomato scion $6 \mathrm{~h}$ after exposure to osmotic stress, assessed by qRT-PCR, Table S1: Sequence of primers used to assess expression of osmotic related genes in potato and tomato homo and heterografts, Table S2: Sequence of used primers in tobacco experiment.

Author Contributions: Y.S.H., S.M.S. and P.K.S. conceived and designed the experiments; Y.S.H. performed the laboratory experiments, data analysis, and wrote the manuscript; M.R.S. provided the plant materials and guidance with grafting; S.M.S. and P.K.S. supervised the study. A.G. and M.M.A. performed ABA quantification. All authors have read and agreed to the published version of the manuscript.

Funding: The funding for this research and APC was provided by the NSERC discovery grant (\#400568) and the Gosling Foundation (\#50294).

Institutional Review Board Statement: Not applicable.

Informed Consent Statement: Not applicable.

Data Availability Statement: All data generated or analyzed during this study are included in this published article and its Supplementary Information Files.

Acknowledgments: The award of scholarship from the Egyptian ministry of higher education to Yasmine Hezema are gratefully acknowledged. We also thank Amelie Charette for her help in quantifying plant hormones and Diana McHenry for her assistance with tobacco regeneration and genetic transformation.

Conflicts of Interest: The authors declare no conflict of interest.

$\begin{array}{ll}\text { Abbreviations } \\ \text { OS } & \text { Osmotic stress } \\ \text { ORGs } & \text { Osmotic-responsive genes } \\ \text { PEG } & \text { Polyethylene glycol } \\ \text { SA } & \text { Salicylic acid } \\ \text { ABA } & \text { Abscisic acid } \\ \text { HSP } & \text { Heat shock protein } \\ \text { NPR1 } & \text { non-expressor of pathogenesis-related (PR) gene 1 } \\ \text { DREB } & \text { Dehydration responsive element binding } \\ \text { WT } & \text { Wild type } \\ \text { CV } & \text { Cell viability } \\ \text { EL } & \text { Electrolyte leakage } \\ \text { RWC } & \text { Relative water content } \\ \text { ROS } & \text { Reactive oxygen species } \\ \mathrm{H}_{2} \mathrm{O}_{2} & \text { Hydrogen peroxide }\end{array}$




\section{References}

1. Gaupels, F.; Vlot, A.C. Plant Defense and Long-Distance Signaling in the Phloem. In Ploem: Molecular Cell Biology, Systemic Communication, Biotic Interactions; Thompson, G.A., van Bel, A.J.E., Eds.; John Wiley \& Sons, Inc.: Hoboken, NJ, USA, 2013; pp. 227-247.

2. Notaguchi, M.; Okamoto, S. Dynamics of long-distance signaling via plant vascular tissues. Front. Plant Sci. 2015, 6, 161. [CrossRef]

3. Shabala, S.; White, R.G.; Djordjevic, M.A.; Ruan, Y.; Mathesius, U. Root-to-shoot signalling: Integration of diverse molecules, pathways and functions. Funct. Plant Biol. 2016, 43, 87-104. [CrossRef]

4. Anjan, K.; Suh, S.; Banerjee, A.K.; Chatterjee, M.; Yu, Y.; Suh, S.; Miller, W.A.; Hannapel, D.J. Dynamics of a Mobile RNA of Potato Involved in a Long-Distance Signaling Pathway. Plant Cell 2006, 18, 3443-3457. [CrossRef]

5. Kudo, H.; Harada, T. A graft-transmissible RNA from tomato rootstock changes leaf morphology of potato scion. HortScience 2007, 42, 225-226. [CrossRef]

6. Jaeger, K.E.; Wigge, P.A.; Lane, C. Report FT Protein Acts as a Long-Range Signal in Arabidopsis. Curr. Biol. 2007, 17, 1050-1054. [CrossRef] [PubMed]

7. Turgeon, R.; Wolf, S. Phloem Transport: Cellular Pathways and Molecular Trafficking. Annu. Rev. Plant Biol. 2009, 60, 207-221. [CrossRef]

8. Notaguchi, M.; Wolf, S.; Lucas, W.J. Phloem-Mobile Aux/IAA Transcripts Target to the Root Tip and Modify Root Architecture. J. Integr. Plant Biol. 2012, 54, 760-772. [CrossRef]

9. Zhao, D.; Song, G.Q. Rootstock-to-scion transfer of transgene-derived small interfering RNAs and their effect on virus resistance in nontransgenic sweet cherry. Plant Biotechnol. J. 2014, 12, 1319-1328. [CrossRef]

10. Spiegelman, Z.; Golan, G.; Wolf, S. Macromolecules Trafficking in the Phloem and Interorgan Communication. Signal. Commun. Plants 2013, 19, 275-290. [CrossRef]

11. Kanehira, A.; Yamada, K.; Iwaya, T.; Ryo, T.; Kasai, A.; Mikio, N.; Harada, T. Apple phloem cells contain some mRNAs transported over long distances. Tree Genet. Genomes 2010, 6, 635-642. [CrossRef]

12. Yang, Y.; Mao, L.; Jittayasothorn, Y.; Kang, Y.; Jiao, C.; Fei, Z. Messenger RNA exchange between scions and rootstocks in grafted grapevines. BMC Plant Biol. 2015, 15, 251. [CrossRef]

13. Duan, X.; Zhang, W.; Huang, J.; Hao, L.; Wang, S.; Wang, A.; Meng, D.; Zhang, Q.; Chen, Q.; Li, T. PbWoxT1 mRNA from pear (Pyrus betulaefolia) undergoes long-distance transport assisted by a polypyrimidine tract binding protein. New Phytol. 2016, 210, 511-524. [CrossRef]

14. Hannapel, D.J. A Model System of Development Regulated by the Long-distance Transport of mRNA. J. Integr. Plant Biol. 2010, 52, 40-52. [CrossRef]

15. Hannapel, D.J.; Banerjee, A.K. Multiple mobile mRNA signals regulate tuber development in potato. Plants 2017, 6, 8. [CrossRef] [PubMed]

16. Cho, S.K.; Sharma, P.; Butler, N.M.; Kang, I.; Shah, S.; Rao, A.G.; Hannapel, D.J. Polypyrimidine tract-binding proteins of potato mediate tuberization through an interaction with StBEL5 RNA. J. Exp. Bot. 2015, 66, 6835-6847. [CrossRef] [PubMed]

17. Xiong, L.; Zhu, J.K. Molecular and genetic aspects of plant responses to osmotic stress. Plant Cell Environ. 2002, 25, 131-139. [CrossRef]

18. Verslues, P.E.; Agarwal, M.; Katiyar-agarwal, S.; Zhu, J.; Zhu, J. Methods and concepts in quantifying resistance to drought, salt and freezing, abiotic stresses that affect plant water status. Plant J. 2006, 45, 523-539. [CrossRef] [PubMed]

19. Cheong, M.S.; Yun, D. Salt-Stress Signaling. J. Plant Biol. 2007, 50, 148-155. [CrossRef]

20. Shinozaki, K.; Yamaguchi-shinozaki, K. Gene networks involved in drought stress response and tolerance. J. Exp. Bot. 2007, 58, 221-227. [CrossRef]

21. Tiwari, R.K.; Lal, M.K.; Naga, K.C.; Kumar, R.; Chourasia, K.N.; Subhash, S.; Kumar, D.; Sharma, S. Emerging roles of melatonin in mitigating abiotic and biotic stresses of horticultural crops. Sci. Hortic. 2020, 272, 109592. [CrossRef]

22. Tiwari, R.K.; Lal, M.K.; Kumar, R.; Chourasia, K.N.; Naga, K.C.; Kumar, D.; Das, S.K.; Zinta, G. Mechanistic insights on melatonin-mediated drought stress mitigation in plants. Physiol. Plant. 2021, 172, 1212-1226. [CrossRef]

23. Chourasia, K.N.; Lal, M.K.; Tiwari, R.K.; Dev, D.; Kardile, H.B.; Patil, V.U.; Kumar, A.; Vanishree, G.; Kumar, D.; Bhardwaj, V.; et al. Salinity Stress in Potato: Understanding Physiological, Biochemical and Molecular Responses. Life 2021, 11, 545. [CrossRef] [PubMed]

24. Li, J.; Besseau, S.; Törönen, P.; Sipari, N.; Kollist, H.; Holm, L.; Palva, E.T. Defense-related transcription factors WRKY70 and WRKY54 modulate osmotic stress tolerance by regulating stomatal aperture in Arabidopsis. New Phytol. 2013, 200, 457-472. [CrossRef] [PubMed]

25. Rajabpoor, S.; Kiani, S.; Sorkheh, K.; Tavakoli, F. Changes induced by osmotic stress in the morphology, biochemistry, physiology, anatomy and stomatal parameters of almond species (Prunus L. spp.) grown in vitro. J. For. Res. 2014, 25, 523-534. [CrossRef]

26. Baldoni, E.; Genga, A.; Cominelli, E. Plant MYB transcription factors: Their role in drought response mechanisms. Int. J. Mol. Sci. 2015, 16, 15811-15851. [CrossRef] [PubMed]

27. Kim, J.S.; Mizoi, J.; Yoshida, T.; Fujita, Y.; Nakajima, J.; Ohori, T.; Todaka, D.; Nakashima, K.; Hirayama, T.; Shinozaki, K.; et al. An ABRE promoter sequence is involved in osmotic stress-responsive expression of the DREB2A gene, which encodes a transcription factor regulating drought-inducible genes in Arabidopsis. Plant Cell Physiol. 2011, 52, 2136-2146. [CrossRef] 
28. Li, C.; Wei, Z.; Liang, D.; Zhou, S.; Li, Y.; Liu, C.; Ma, F. Enhanced salt resistance in apple plants overexpressing a Malus vacuolar $\mathrm{Na}+/ \mathrm{H}+$ antiporter gene is associated with differences in stomatal behavior and photosynthesis. Plant Physiol. Biochem. 2013, 70, 164-173. [CrossRef]

29. Dong, Q.; Zheng, W.; Duan, D.; Huang, D.; Wang, Q.; Liu, C.; Li, C.; Gong, X.; Li, C.; Mao, K.; et al. MdWRKY30, a group IIa WRKY gene from apple, confers tolerance to salinity and osmotic stresses in transgenic apple callus and Arabidopsis seedlings. Plant Sci. 2020, 299, 110611. [CrossRef] [PubMed]

30. Yang, H.; Zhao, L.; Zhao, S.; Wang, J.; Shi, H. Biochemical and transcriptomic analyses of drought stress responses of LY1306 tobacco strain. Sci. Rep. 2017, 7, 1-10. [CrossRef]

31. Park, H.Y.; Seok, H.Y.; Park, B.K.; Kim, S.H.; Goh, C.H.; Lee, B.H.; Lee, C.H.; Moon, Y.H. Overexpression of Arabidopsis ZEP enhances tolerance to osmotic stress. Biochem. Biophys. Res. Commun. 2008, 375, 80-85. [CrossRef]

32. Soares-Cavalcanti, N.M.; Belarmino, L.C.; Kido, E.A.; Wanderley-Nogueira, A.C.; Bezerra-Neto, J.P.; Cavalcanti-Lira, R.; Pandolfi, V.; Nepomuceno, A.L.; Abdelnoor, R.V.; Nascimento, L.C.; et al. In silico identification of known osmotic stress responsive genes from Arabidopsis in Soybean and Medicago. Genet. Mol. Biol. 2012, 35, 315-321. [CrossRef]

33. Osakabe, Y.; Arinaga, N.; Umezawa, T.; Katsura, S.; Nagamachi, K.; Tanaka, H.; Ohiraki, H.; Yamada, K.; Seo, S.U.; Abo, M.; et al. Osmotic stress responses and plant growth controlled by potassium transporters in Arabidopsis. Plant Cell 2013, 25, 609-624. [CrossRef]

34. Mahouachi, J.; Arbona, V.; Gomez-Cadenas, A. Hormonal changes in papaya seedlings subjected to progressive water stress and re-watering. Plant Growth Regul. 2007, 53, 43-51. [CrossRef]

35. Marcińska, I.; Czyczyło-Mysza, I.; Skrzypek, E.; Grzesiak, M.T.; Janowiak, F.; Filek, M.; Dziurka, M.; Dziurka, K.; Waligórski, P.; Juzoń, K.; et al. Alleviation of osmotic stress effects by exogenous application of salicylic or abscisic acid on wheat seedlings. Int. J. Mol. Sci. 2013, 14, 13171-13193. [CrossRef]

36. Schachtman, D.P.; Goodger, J.Q.D. Chemical root to shoot signaling under drought. Trends Plant Sci. 2008, 13, 281-287. [CrossRef]

37. McAdam, S.A.M.; Brodribb, T.J.; Ross, J.J. Shoot-derived abscisic acid promotes root growth. Plant Cell Environ. 2016, 39, 652-659. [CrossRef]

38. Dong, H.; Niu, Y.; Li, W.; Zhang, D. Effects of cotton rootstock on endogenous cytokinins and abscisic acid in xylem sap and leaves in relation to leaf senescence. J. Exp. Bot. 2008, 59, 1295-1304. [CrossRef] [PubMed]

39. Li, W.; de Ollas, C.; Dodd, I.C. Long-distance ABA transport can mediate distal tissue responses by affecting local ABA concentrations. J. Integr. Plant Biol. 2018, 60, 16-33. [CrossRef]

40. Louws, F.J.; Rivard, C.L.; Kubota, C. Grafting fruiting vegetables to manage soilborne pathogens, foliar pathogens, arthropods and weeds. Sci. Hortic. 2010, 127, 127-146. [CrossRef]

41. Koepke, T.; Dhingra, A. Rootstock scion somatogenetic interactions in perennial composite plants. Plant Cell Rep. 2013, 32, 1321-1337. [CrossRef] [PubMed]

42. Schwarz, D.; Rouphael, Y.; Colla, G.; Henk, J. Grafting as a tool to improve tolerance of vegetables to abiotic stresses: Thermal stress, water stress and organic pollutants. Sci. Hortic. 2010, 127, 162-171. [CrossRef]

43. Sánchez-Rodríguez, E.; Romero, L.; Ruiz, J.M. Role of Grafting in Resistance to Water Stress in Tomato Plants: Ammonia Production and Assimilation. J. Plant Growth Regul. 2013, 32, 831-842. [CrossRef]

44. Smolka, A.; Li, X.-Y.; Heiklt, C.; Welander, M.; Zhu, L. Effects of transgenic rootstocks on growth and development of nontransgenic scion cultivars in apple. Transgen. Res. 2010, 19, 933-948. [CrossRef] [PubMed]

45. Albacete, A.; Martínez-Andújar, C.; Martínez-Pérez, A.; Thompson, A.J.; Dodd, I.C.; Pérez-Alfocea, F. Unravelling rootstock $\times$ scion interactions to improve food security. J. Exp. Bot. 2015, 66, 2211-2226. [CrossRef] [PubMed]

46. Artlip, T.S.; Wisniewski, M.E.; Arora, R.; Norelli, J.L. An apple rootstock overexpressing a peach CBF gene alters growth and flowering in the scion but does not impact cold hardiness or dormancy. Hortic. Res. 2016, 3, 16006. [CrossRef]

47. Jeannine, K.; Piyum, A.; James, H. Cross-Species Translocation of mRNA from Host Plants into the Parasitic Plant Dodder1. Plant Physiol. 2007, 143, 1037-1043. [CrossRef]

48. Xu, H.; Zhang, W.; Li, M.; Harada, T.; Han, Z.; Li, T. Gibberellic acid insensitive mRNA transport in both directions between stock and scion in Malus. Tree Genet. Genomes 2010, 6, 1013-1019. [CrossRef]

49. Xu, H.; Iwashiro, R.; Li, T.; Harada, T. Long-distance transport of Gibberellic Acid Insensitive mRNA in Nicotiana benthamiana. BMC Plant Biol. 2013, 13, 165. [CrossRef] [PubMed]

50. Haroldsen, V.M.; Szczerba, M.W.; Aktas, H.; Lopez-Baltazar, J.; Odias, M.J.; Chi-ham, C.L.; Labavitch, J.M.; Bennett, A.B.; Powell, A.L.T. Mobility of transgenic nucleic acids and proteins within grafted rootstocks for agricultural improvement. Front. Plant Sci. 2012, 3, 1-12. [CrossRef]

51. Nakashima, K.; Yamaguchi-Shinozaki, K. Regulons involved in osmotic stress-responsive and cold stress-responsive gene expression in plants. Physiol. Plant 2006, 126, 62-71. [CrossRef]

52. Wahid, A.; Gelani, S.; Ashraf, M.; Foolad, M.R. Heat tolerance in plants: An overview. Environ. Exp. Bot. 2007, 61, 199-223. [CrossRef]

53. Penfield, S. Temperature perception and signal transduction in plants. New Phytol. 2008, 179, 615-628. [CrossRef]

54. Frank, G.; Pressman, E.; Ophir, R.; Althan, L.; Shaked, R.; Freedman, M.; Shen, S.; Firon, N. Transcriptional profiling of maturing tomato (Solanum lycopersicum L.) microspores reveals the involvement of heat shock proteins, ROS scavengers, hormones, and sugars in the heat stress response. J. Exp. Bot. 2009, 60, 3891-3908. [CrossRef] [PubMed] 
55. Aneja, B.; Yadav, N.R.; Kumar, N.; Yadav, R.C. HSP transcript induction is correlated with physiological changes under drought stress in Indian mustard. Physiol. Mol. Biol. Plants 2015, 21, 305-316. [CrossRef]

56. Singh, R.K.; Jaishankar, J.; Muthamilarasan, M.; Shweta, S.; Dangi, A.; Prasad, M. Genome-wide analysis of heat shock proteins in C4 model, foxtail millet identifies potential candidates for crop improvement under abiotic stress. Sci. Rep. 2016, 6, 1-14. [CrossRef] [PubMed]

57. Sun, X.; Sun, C.; Li, Z.; Hu, Q.; Han, L.; Luo, H. AsHSP17, A creeping bentgrass small heat shock protein modulates plant photosynthesis and ABA-dependent and independent signalling to attenuate plant response to abiotic stress. Plant Cell Environ. 2016, 39, 1320-1337. [CrossRef] [PubMed]

58. Yin, F.; Qin, C.; Gao, J.; Liu, M.; Luo, X.; Zhang, W.; Liu, H.; Liao, X.; Shen, Y.; Mao, L.; et al. Genome-Wide Identification and Analysis of Drought-Responsive Genes and MicroRNAs in Tobacco. Int. J. Mol. Sci. 2015, 16, 5714-5740. [CrossRef] [PubMed]

59. Nakashima, K.; Yamaguchi-Shinozaki, K.; Shinozaki, K. The transcriptional regulatory network in the drought response and its crosstalk in abiotic stress responses including drought, cold, and heat. Front. Plant Sci. 2014, 5, 1-7. [CrossRef] [PubMed]

60. Jia, H.; Zhang, S.; Ruan, M.; Wang, Y.; Wang, C. Analysis and application of RD29 genes in abiotic stress response. Acta Physiol. Plant. 2012, 34, 1239-1250. [CrossRef]

61. Kasuga, M.; Liu, Q.; Miura, S.; Yamaguchi-shinozaki, K.; Shinozaki, K. Improving plant drought, salt, and freezing tolerance by gene transfer of a single stress-inducible transcription factor. Nat. Biotechnol. 1999, 17, 287-291. [CrossRef]

62. Maruyama, K.; Sakuma, Y.; Kasuga, M.; Ito, Y.; Seki, M.; Goda, H.; Shimada, Y.; Yoshida, S.; Shinozaki, K.; Yamaguchi-Shinozaki, K Identification of cold-inducible downstream genes of the Arabidopsis DREB1A/CBF3 transcriptional factor using two microarray systems. Plant J. 2004, 38, 982-993. [CrossRef]

63. Rehman, S.; Mahmood, T. Functional role of DREB and ERF transcription factors: Regulating stress-responsive network in plants. Acta Physiol. Plant. 2015, 37, 178. [CrossRef]

64. Chen, H.; Liu, L.; Wang, L.; Wang, S.; Cheng, X. VrDREB2A, a DREB—Binding transcription factor from Vigna radiata, increased drought and high-salt tolerance in transgenic Arabidopsis thaliana. J. Plant Res. 2016, 129, 263-273. [CrossRef] [PubMed]

65. Li, F.; Han, Y.; Feng, Y.; Xing, S.; Zhao, M.; Chen, Y.; Wang, W. Expression of wheat expansin driven by the RD29 promoter in tobacco confers water-stress tolerance without impacting growth and development. J. Biotechnol. 2013, 163, 281-291. [CrossRef]

66. Kiyosue, T.; Yamaguchi-Shinozaki, K.; Shinozaki, K. Cloning of cDNAs for genes that are early-responsive to dehydration stress (ERDs) in Arabidopsis thaliana L.: Identification of three ERDs as HSP cognate genes. Plant Mol. Biol. 1994, 25, 791-798. [CrossRef]

67. Kimura, M.; Yamamoto, Y.Y.; Seki, M.; Sakurai, T.; Sato, M.; Abe, T.; Yoshida, S.; Manabe, K.; Shinozaki, K.; Matsui, M. Rapid Communication Identification of Arabidopsis Genes Regulated by High Light-Stress Using cDNA Microarray. Photochem. Photobiol. 2003, 77, 226-233.

68. Munné-Bosch, S.; Alegre, L. Die and let live: Leaf senescence contributes to plant survival under drought stress. Funct. Plant Biol. 2004, 31, 203-216. [CrossRef]

69. Agarwal, P.K.; Agarwal, P.; Reddy, M.K.; Sopory, S.K. Role of DREB transcription factors in abiotic and biotic stress tolerance in plants. Plant Cell Rep. 2006, 25, 1263-1274. [CrossRef]

70. Li, R.; Liu, C.; Zhao, R.; Wang, L.; Chen, L.; Yu, W.; Zhang, S.; Sheng, J.; Shen, L. CRISPR/Cas9-Mediated SINPR1 mutagenesis reduces tomato plant drought tolerance. BMC Plant Biol. 2019, 19, 38. [CrossRef]

71. Wu, Y.; Zhang, D.; Chu, J.Y.; Boyle, P.; Wang, Y.; Brindle, I.D.; De Luca, V.; Després, C. The Arabidopsis NPR1 Protein Is a Receptor for the Plant Defense Hormone Salicylic Acid. Cell Rep. 2012, 1, 639-647. [CrossRef]

72. Jin, H.; Cominelli, E.; Bailey, P.; Parr, A.; Mehrtens, F.; Jones, J.; Tonelli, C.; Weisshaar, B.; Martin, C. Transcriptional repression by AtMYB4 controls production of UV-protecting sunscreens in Arabidopsis. EMBO J. 2000, 19, 6150-6161. [CrossRef]

73. Storozhenko, S.; De Pauw, P.; Van Montagu, M.; Inze, D.; Kushnir, S. The Heat-Shock Element Is a Functional Component of the Arabidopsis APX1 Gene Promoter 1. Plant Physiol. 1998, 118, 1005-1014. [CrossRef]

74. Wang, W.; Vinocur, B.; Shoseyov, O.; Altman, A. Role of plant heat-shock proteins and molecular chaperones in the abiotic stress response. Trends Plant Sci. 2004, 9, 244-252. [CrossRef]

75. Sakamoto, H.; Maruyama, K.; Sakuma, Y.; Meshi, T.; Iwabuchi, M.; Shinozaki, K.; Yamaguchi-Shinozaki, K. Arabidopsis Cys2/His2Type Zinc-Finger Proteins Function as Transcription Repressors under Drought. Plant Physiol. 2004, 136, 2734-2746. [CrossRef]

76. Bowles, D.; Lim, E.; Poppenberger, B.; Vaistij, E. Glycosyltransferases of Lipophilic Small Molecules. Annu. Rev. Plant Biol. 2006, 57, 568-597. [CrossRef]

77. Shi, H.; Liu, W.; Yao, Y.; Wei, Y.; Chan, Z. Alcohol dehydrogenase 1 (ADH1) confers both abiotic and biotic stress resistance in Arabidopsis. Plant Sci. 2017, 262, 24-31. [CrossRef] [PubMed]

78. Jones, P.; Vogt, T. Glycosyltransferases in secondary plant metabolism: Tranquilizers and stimulant controllers. Planta 2001, 213, 164-174. [CrossRef] [PubMed]

79. Bowles, D.; Isayenkova, J.; Lim, E. Glycosyltransferases: Managers of small molecules. Curr. Opin. Plant Biol. 2005, 8, 254-263. [CrossRef]

80. Sun, X.P.; Yan, H.L.; Kang, X.Y.; Ma, F.W. Growth, gas exchange, and water-use efficiency response of two young apple cultivars to drought stress in two scion-one rootstock grafting system. Photosynthetica 2013, 51, 404-410. [CrossRef]

81. Abe, H.; Yamaguchi-shinozaki, K.; Urao, T.; Hosokawa, C.D. Role of Arabidopsis MYC and MYB Homologs in Drought- and Abscisic Acid-Regulated Gene Expression. Plant Cell 1997, 9, 1859-1869.

82. Harada, T. Grafting and RNA transport via phloem tissue in horticultural plants. Sci. Hortic. 2010, 125, 545-550. [CrossRef] 
83. Zhang, W.N.; Duan, X.W.; Ma, C.; Harada, T.; Li, T.Z. Transport of mRNA molecules coding NAC domain protein in grafted pear and transgenic tobacco. Biol. Plant. 2013, 57, 224-230. [CrossRef]

84. Thieme, C.J.; Rojas-Triana, M.; Stecyk, E.; Schudoma, C.; Zhang, W.; Yang, L.; Miñambres, M.; Walther, D.; Schulze, W.X.; Paz-Ares, J.; et al. Endogenous Arabidopsis messenger RNAs transported to distant tissues. Nat. Plants 2015, 1, 15025. [CrossRef]

85. Notaguchi, M.; Higashiyama, T.; Suzuki, T. Identification of mRNAs that move over long distances using an RNA-Seq analysis of Arabidopsis/Nicotiana benthamiana heterografts. Plant Cell Physiol. 2015, 56, 311-321. [CrossRef]

86. Pallas, V.; Gómez, G. Phloem RNA-binding proteins as potential components of the long-distance RNA transport system. Front. Plant Sci. 2013, 4, 1-6. [CrossRef]

87. Banerjee, A.K.; Lin, T.; Hannapel, D.J. Untranslated Regions of a Mobile Transcript Mediate. Plant Physiol. 2009, 151, 1831-1843. [CrossRef]

88. Hannapel, D.J. Long-Distance Systemic Signaling and Communication in Plants; Long-Distance Signaling via Mobile RNAs; Springer Nature Switzerland AG: Cham, Switzerland, 2013; pp. 53-70. ISBN 9783642364709.

89. Cao, H.; Glazebrook, J.; Clarke, J.D.; Volko, S.; Dong, X. The Arabidopsis NPR1 gene that controls systemic acquired resistance encodes a novel protein containing ankyrin repeats. Cell 1997, 88, 57-63. [CrossRef]

90. Yasuda, M.; Ishikawa, A.; Jikumaru, Y.; Seki, M.; Umezawa, T.; Asami, T.; Maruyama-Nakashita, A.; Kudo, T.; Shinozaki, K.; Yoshida, S.; et al. Antagonistic interaction between systemic acquired resistance and the abscisic acid-mediated abiotic stress response in Arabidopsis. Plant Cell 2008, 20, 1678-1692. [CrossRef]

91. Ding, Y.; Sun, T.; Ao, K.; Peng, Y.; Zhang, Y.; Li, X.; Zhang, Y. Opposite Roles of Salicylic Acid Receptors NPR1 and NPR3/NPR4 in Transcriptional Regulation of Plant Immunity. Cell 2018, 173, 1454-1467.e10. [CrossRef]

92. Pajerowska-Mukhtar, K.M.; Emerine, D.K.; Mukhtar, M.S. Tell me more: Roles of NPRs in plant immunity. Trends Plant Sci. 2013, 18, 402-411. [CrossRef]

93. Sharma, V.; Goel, P.; Kumar, S.; Singh, A.K. An apple transcription factor, MdDREB76, confers salt and drought tolerance in transgenic tobacco by activating the expression of stress-responsive genes. Plant Cell Rep. 2019, 38, 221-241. [CrossRef]

94. Singh, V.K.; Mishra, A.; Haque, I.; Jha, B. A novel transcription factor-like gene SbSDR1 acts as a molecular switch and confers salt and osmotic endurance to transgenic tobacco. Sci. Rep. 2016, 6, 31686. [CrossRef]

95. Bouaziz, D.; Pirrello, J.; Charfeddine, M.; Hammami, A.; Jbir, R.; Dhieb, A.; Bouzayen, M.; Gargouri-bouzid, R. Overexpression of StDREB1 Transcription Factor Increases Tolerance to Salt in Transgenic Potato Plants. Mol Biotechnol 2013, 54, 803-817. [CrossRef] [PubMed]

96. Mishra, A.; Jha, B. Overexpression of a Cytosolic Abiotic Stress Responsive Universal Stress Protein (Sb USP) Mitigates Salt and Osmotic Stress in Transgenic Tobacco Plants. Front. Plant Sci. 2016, 7, 518. [CrossRef]

97. Jayakannan, M.; Bose, J.; Babourina, O.; Shabala, S.; Massart, A.; Poschenrieder, C.; Rengel, Z. The NPR1-dependent salicylic acid signalling pathway is pivotal for enhanced salt and oxidative stress tolerance in Arabidopsis. J. Exp. Bot. 2015, 66, 1865-1875. [CrossRef]

98. Liang, Y.; Li, X.; Zhang, D.; Gao, B.; Yang, H.; Wang, Y.; Guan, K.; Wood, A.J. Plant Physiology and Biochemistry ScDREB8, a novel A-5 type of DREB gene in the desert moss Syntrichia caninervis, confers salt tolerance to Arabidopsis. Plant Physiol. Biochem. 2017, 120, 242-251. [CrossRef] [PubMed]

99. Kumar, R.; Gupta, A.; Soni, D.; Garg, R.; Pathre, U. V Ectopic expression of a tomato DREB gene affects several ABA processes and in fluences plant growth and root architecture in an age-dependent manner. J. Plant Physiol. 2017, 214, 97-107. [CrossRef]

100. Apel, K.; Hirt, H. Reactive oxygen species: Metabolism, Oxidative Stress, and Signal Transduction. Annu. Rev. Plant Biol. 2004, 55, 373-399. [CrossRef]

101. Taiz, L.; Zeiger, E. Plant Physiology, 3rd ed.; Sinauer Associates: Sunderland, MA, USA, 2003; ISBN 0878938230.

102. Van Breusegem, F.; Dat, J.F. Reactive Oxygen Species in Plant Cell Death 1. Plant Physiol. 2006, 141, 384-390. [CrossRef]

103. Soar, C.J.; Dry, P.R.; Loveys, B.R. Scion photosynthesis and leaf gas exchange in Vitis vinifera L. cv. Shiraz: Mediation of rootstock effects via xylem sap ABA. Aust. J. Grapes Wine Res. 2006, 12, 82-96. [CrossRef]

104. Ke, Y.G.; Yang, Z.J.; Yu, S.W.; Li, T.F.; Wu, J.H.; Gao, H.; Fu, Y.P.; Luo, L.J. Characterization of OsDREB6 responsive to osmotic and cold stresses in rice. J. Plant Biol. 2014, 57, 150-161. [CrossRef]

105. Liu, B.; Zhou, Y.; Lan, W.; Zhou, Q.; Li, F.; Chen, F.; Bao, M.; Liu, G. LIDREB1G, a novel DREB subfamily gene from Lilium longiflorum, can enhance transgenic Arabidopsis tolerance to multiple abiotic stresses. Plant Cell Tissue Organ Cult. 2019, 138, 489-506. [CrossRef]

106. Mehrotra, R.; Bhalothia, P.; Bansal, P.; Basantani, M.K.; Bharti, V.; Mehrotra, S. Abscisic acid and abiotic stress tolerance-Different tiers of regulation. J. Plant Physiol. 2014, 171, 486-496. [CrossRef] [PubMed]

107. Timperio, A.M.; Egidi, M.G.; Zolla, L. Proteomics applied on plant abiotic stresses: Role of heat shock proteins (HSP). J. Proteom. 2008, 71, 391-411. [CrossRef]

108. Jumali, S.S.; Said, I.M.; Ismail, I.; Zainal, Z. Genes induced by high concentration of salicylic acid in Mitragyna speciosa. Aust. J. Crop Sci. 2011, 5, 296-303.

109. Olate, E.; Jiménez-Gómez, J.M.; Holuigue, L.; Salinas, J. Acclimation by interacting with HSFA1 factors. Nat. Plants 2018, 4 , 811-823. [CrossRef]

110. Murashige, T.; Skoog, F. A Revised Medium for Rapid Growth and Bio Assays with Tobacco Tissue Cultures. Physiol. Plant. 1962, 15, 473-497. [CrossRef] 
111. Expósito-Rodríguez, M.; Borges, A.A.; Borges-Pérez, A.; Pérez, J.A. Selection of internal control genes for quantitative real-time RT-PCR studies during tomato development process. BMC Plant Biol. 2008, 8, 131. [CrossRef]

112. Horsch, R.B.; Fraley, R.T.; Rogers, S.G.; Sanders, P.R.; Lloyd, A.; Hoffmann, N. Inheritance of functional foreign genes in plants. Am. Assoc. Adv. Sci. 1984, 223, 496-498. [CrossRef] [PubMed]

113. Horsch, A.R.B.; Fry, J.E.; Hoffman, N.L.; Eichholtz, D.; Rogers, S.G.; Fraley, R.T. A simple and general method for transferring genes into plants. Am. Assoc. Adv. Sci. 1985, 227, 1229.

114. Singla-Pareek, S.L.; Reddy, M.K.; Sopory, S.K. Genetic engineering of the glyoxalase pathway in tobacco leads to enhanced salinity tolerance. Proc. Natl. Acad. Sci. USA 2003, 100, 14672-14677. [CrossRef]

115. Bajji, M.; Kinet, J.M.; Lutts, S. The use of the electrolyte leakage method for assessing cell membrane stability as a water stress tolerance test in durum wheat. Plant Growth Regul. 2002, 36, 61-70. [CrossRef]

116. Hema, R.; Vemanna, R.S.; Sreeramulu, S.; Reddy, C.P.; Senthil-Kumar, M.; Udayakumar, M. Stable expression of mtlD gene imparts multiple stress tolerance in finger millet. PLoS ONE 2014, 9, e99110. [CrossRef] [PubMed]

117. Lichtenthaler, H. Chlorophylls and carotenoids: Pigments of photosynthetic biomembranes. Methods Enzymol. 1987, 148, 350-382. [CrossRef]

118. Daudi, A.; O’Brien, J.A. Detection of Hydrogen Peroxide by DAB Staining in Arabidopsis Leaves. Bio-Protocol 2012, 2, e263. [CrossRef]

119. Patterson, B.D.; MacRae, E.A.; Ferguson, I.B. Estimation of hydrogen peroxide in plant extracts using titanium(IV). Anal. Biochem. 1984, 139, 487-492. [CrossRef]

120. Ayyanath, M.M.; Shukla, M.R.; Saxena, P.K. Role of water percolation in reproductive physiology of hazelnut (Corylus spp.). Environ. Exp. Bot. 2021, 182, 104278. [CrossRef]

121. Erland, L.A.E.; Shukla, M.R.; Glover, W.B.; Saxena, P.K. A simple and efficient method for analysis of plant growth regulators: A new tool in the chest to combat recalcitrance in plant tissue culture. Plant Cell. Tissue Organ Cult. 2017, 131, 459-470. [CrossRef]

122. Gasic, K.; Hernandez, A.; Korban, S.S. RNA Extraction From Different Apple Tissues Rich in Polyphenols and Polysaccharides for cDNA. Plant Mol. Biol. Report. 2004, 22, 437a-437g. [CrossRef] 